NASA/TP-2000-210538

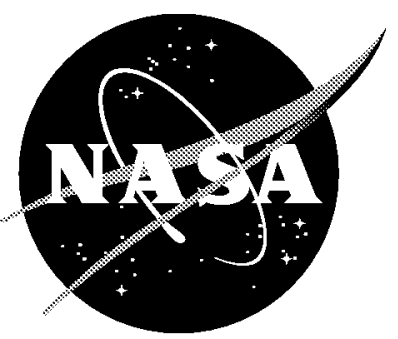

\title{
Effective Widths of Compression-Loaded Plates With a Cutout
}

Mark W. Hilburger, Michael P. Nemeth and James H. Starnes, Jr.

Langley Research Center, Hampton, Virginia 


\section{The NASA STI Program Office ... in Profile}

Since its founding, NASA has been dedicated to the advancement of aeronautics and space science. The NASA Scientific and Technical Information (STI) Program Office plays a key part in helping NASA maintain this important role.

The NASA STI Program Office is operated by Langley Research Center, the lead center for NASA's scientific and technical information. The NASA STI Program Office provides access to the NASA STI Database, the largest collection of aeronautical and space science STI in the world. The Program Office is also NASA's institutional mechanism for disseminating the results of its research and development activities. These results are published by NASA in the NASA STI Report Series, which includes the following report types:

- TECHNICAL PUBLICATION. Reports of completed research or a major significant phase of research that present the results of NASA programs and include extensive data or theoretical analysis. Includes compilations of significant scientific and technical data and information deemed to be of continuing reference value. NASA counterpart of peer-reviewed formal professional papers, but having less stringent limitations on manuscript length and extent of graphic presentations.

- TECHNICAL MEMORANDUM. Scientific and technical findings that are preliminary or of specialized interest, e.g., quick release reports, working papers, and bibliographies that contain minimal annotation. Does not contain extensive analysis.

- CONTRACTOR REPORT. Scientific and technical findings by NASA-sponsored contractors and grantees.
- CONFERENCE PUBLICATION. Collected papers from scientific and technical conferences, symposia, seminars, or other meetings sponsored or co-sponsored by NASA.

- SPECIAL PUBLICATION. Scientific, technical, or historical information from NASA programs, projects, and missions, often concerned with subjects having substantial public interest.

- TECHNICAL TRANSLATION. Englishlanguage translations of foreign scientific and technical material pertinent to NASA's mission.

Specialized services that complement the STI Program Office's diverse offerings include creating custom thesauri, building customized databases, organizing and publishing research results ... even providing videos.

For more information about the NASA STI Program Office, see the following:

- Access the NASA STI Program Home Page at http://www.sti.nasa.gov

- E-mail your question via the Internet to help@sti.nasa.gov

- Fax your question to the NASA STI Help Desk at (301) 621-0134

- Phone the NASA STI Help Desk at (301) 621-0390

- Write to: NASA STI Help Desk NASA Center for AeroSpace Information 7121 Standard Drive Hanover, MD 21076-1320 
NASA/TP-2000-210538

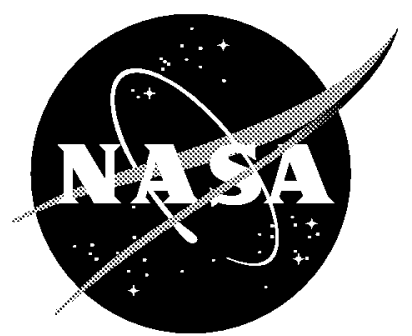

\section{Effective Widths of Compression-Loaded Plates With a Cutout}

Mark W. Hilburger, Michael P. Nemeth and James H. Starnes, Jr.

Langley Research Center, Hampton, Virginia

National Aeronautics and

Space Administration

Langley Research Center

Hampton, Virginia 23681-2199 
Available from:

NASA Center for AeroSpace Information (CASI)

7121 Standard Drive

Hanover, MD 21076-1320

(301) 621-0390
National Technical Information Service (NTIS) 5285 Port Royal Road

Springfield, VA 22161-2171

(703) 605-6000 


\begin{abstract}
Results from a study of the effects of cutouts and laminate construction on the prebuckling and initial postbuckling stiffnesses, and the effective widths of compression-loaded laminated-composite and aluminum square plates are presented. An effective-width concept is derived for plates with and without cutouts, and experimental and nonlinear finite-element analysis results are presented. Behavioral trends are compared for seven plate families and for cutout-diameter-to-plate-width ratios up to 0.66. A general compact design curve that can be used to present and compare the effective widths for a wide. range of laminate constructions is also presented. A discussion of how the results can be used and extended to include certain types of damage, cracks, and other structural discontinuities or details is given. Several behavioral trends are described that initially appear to be nonintuitive. The results demonstrate a complex interaction between cutout size and plate orthotropy that affects the axial stiffness and effective width of a plate subjected to compression loads.
\end{abstract}

\section{Introduction}

Efficient, lightweight, stiffened panels that are subjected to compression loads are often designed to take advantage of the postbuckling stiffness and strength of their plate elements. More specifically, the flat plate elements exhibit stable postbuckling behavior and, as a result, can often support loads significantly greater than their buckling load. Prior to buckling, the axial stresses in each plate element are typically uniform across the width of a compression-loaded plate. When a flat plate element buckles, the axial stiffness of the central region of the plate element is reduced as a result of the corresponding bending deformations, and the internal axial load path is redistributed from the central region of the plate element toward the adjacent stiffeners of the stiffened panel. Thus, the stiffened panel behaves as if the load is supported by the stiffeners and by a portion of the plate elements adjacent to each stiffener. The width of a plate element that effectively supports part of the applied load is known as the effective width of the plate. ${ }^{1-4}$

Historically, the effective-width concept appears to have originated in the design of ship plating. ${ }^{2}$ Around 1932, von Kármán, Sechler, and Donnell became the first to apply the effective-width concept to all-metal aircraft construction. ${ }^{1}$ The motivation for this work was to establish a simple design-oriented analysis that approximates the stiffness of the buckled plate elements in the calculation of the stiffener strength and the ultimate load capacity of the stiffened panel. Designing a panel to allow plate buckling above a specified design load provides a lighter weight panel because the plate will be thinner than a plate designed to resist buckling. Currently, the effective-width concept remains in use as an important preliminary design tool, not only for metallic, stiffened aircraft panels, but also for laminated composite stiffened aircraft panels.

A common structural detail that is present in many stiffened panels is a cutout. For example, cutouts are used to reduce weight, to provide access to various locations inside an aircraft, and to permit hydraulic and electrical lines to pass through the structure. Thus, the effect of a cutout on the postbuckling behavior of a plate and its effective width is important in the design of aircraft structures. A recent survey of the postbuckling behavior of plates with a cutout is given in Ref. 5 and indicates that the effect of a cutout on the effective-width of a plate has received relatively little attention, compared to plate buckling behavior.

The present paper describes the results of a study of the effects of cutouts and laminate construction on the prebuckling and initial postbuckling responses and the effective width of compression-loaded, symmetrically laminatedcomposite plates and aluminum plates. In particular, the behavior of square plates that are subjected to a uniform edge displacement is presented. First, the effective-width concept is presented in terms of prebuckling and initial postbuckling stiffnesses of a plate, and is then extended to include plates with a cutout. Then, results are presented for the effective width of aluminum and graphite-epoxy plates that are based on the experimentally measured prebuckling and postbuckling stiffnesses that have been presented in Refs. 6 and 7. Next, results obtained by using the STAGS finite-element analysis code ${ }^{8}$ are presented for corresponding geometrically perfect plates with nominal dimensions and idealized boundary and loading conditions. Behavioral trends that are exhibited by the experimental and finite-element analysis results are then presented and compared for aluminum plates and for composite plates with six laminate families and cutout-diameter-to-plate-width ratios $\mathrm{d} / \mathrm{W}$ ranging from 0 to 0.66 . In addition, a general, compact design curve that can be used to present and compare the effective widths of a wide range of laminated-composite plate constructions is presented. A discussion of how the results can be used and extended to include certain types of centralized damage, cracks, and other structural discontinuities or details that affect the axial stiffness of a plate is also presented. 


\section{Background and Analysis}

The effective-width concept is based on the behavior of plates that are subcomponents of a stiffened structural configuration, such as a wing or fuselage, that are loaded in compression. In particular, the concept was developed for a plate subcomponent that is attached to two stiff frames and two less stiff stringers, and that is surrounded by other similar panels, frames, and stringers. For this arrangement, the effective-width concept assumes that the plate edges remain straight during loading; because of the stiffness provided by the adjacent structure. However, the effective width concept can also be applied to plates that are supported such that the unloaded edges are free to deform in the plane of the plate. This type of support condition is often simulated in the laboratory (e.g., Ref. 6) and is the focus of the present study.

The effective-width concept, at the plate subcomponent level, is based on the redistribution of the axial stress resultant, $\mathrm{N}_{\mathrm{x}}$, at the loaded edges when a compression-loaded plate buckles, as illustrated in Fig. 1. For example, a perfectly flat compression-loaded plate with simply-supported edges remains flat and $\mathrm{N}_{\mathrm{x}}$ is uniformly distributed across the loaded edges prior to buckling (Fig. 1(c)). When the plate buckles, a significant portion of the plate's central region exhibits relatively large out-of-plane displacements which reduce the effective axial stiffness (Fig. 1(b)). When the stiffness of the central region of the plate is reduced, the internal loads are redistributed toward the side supports and $\mathrm{N}_{\mathrm{x}}$ becomes nonuniform across the loaded edges (Fig. 1(d)). This change in internal load distribution corresponds to the abrupt change in slope of the load versus end-shortening curve shown in Fig. 1(b). A common practice in the preliminary design of stiffened panels is to replace the nonuniform $\mathrm{N}_{\mathrm{x}}$ distribution at the loaded edges with a uniform load distribution $\left(\mathrm{N}_{\mathrm{x}}\right)_{\max }$ over a reduced width $\mathrm{W}_{\mathrm{e}}$ (the effective width), as shown in Fig. 2. This approximation is often used to estimate the required strength of stringers for postbuckling strength and represents a simple way to incorporate nonlinear behavior into a design. The symbol $\left(\mathrm{N}_{\mathrm{x}}\right)_{\max }$ represents the maximum value of $\mathrm{N}_{\mathrm{x}}$ that occurs at the loaded edges of a plate (Fig. 2(a)). The value of $W_{e}$ is determined by equating the load $P$ that acts on the plate with the load given by $\left(\mathrm{N}_{\mathrm{x}}\right)_{\max }$ times the effective width (see Ref. 4); that is

$$
\mathrm{P}=\int_{0}^{\mathrm{W}} \mathrm{N}_{\mathrm{x}} \mathrm{dy}=\left(\mathrm{N}_{\mathrm{x}}\right)_{\max } \mathrm{W}_{\mathrm{e}}
$$

Following Ref. 9, Eq. (1) is written as

$$
\frac{\mathrm{W}_{\mathrm{e}}}{\mathrm{W}}=\frac{\mathrm{P}}{\left(\mathrm{N}_{\mathrm{x}}\right)_{\max } \mathrm{W}}
$$

in which the term $\left(\mathrm{N}_{\mathrm{x}}\right)_{\max } \mathrm{W}$ is interpreted as the load in an unbuckled plate, corresponding to a given value of postbuckling end-shortening $\Delta$, if the plate was unbuckled. This interpretation of Eq. (1) is illustrated in Fig. 3, where $\mathrm{P}_{0}^{*}=\left(\mathrm{N}_{\mathrm{x}}\right)_{\max } \mathrm{W}$. Thus, the ratio of the effective width to the actual width is expressed as

$$
\frac{\mathrm{W}_{\mathrm{e}}}{\mathrm{W}}=\frac{\mathrm{P}}{\mathrm{P}_{0}^{*}}
$$

The experimental results that are presented in Refs. 6 and 7 indicate that in many cases the postbuckling branch of the load versus end-shortening curves for elastic plates remains essentially linear for loads up to nearly twice the buckling load. With the aid of Fig. 3, the ratio of the effective width to the actual width for bilinear load versus endshortening curves can be expressed in terms of the prebuckling stiffness, $S_{0}^{*}$, and the postbuckling stiffness $S^{*}$ by either of the following equations

$$
\begin{gathered}
\frac{\mathrm{W}_{\mathrm{e}}}{\mathrm{W}}=\frac{\varepsilon_{\mathrm{cr}}}{\varepsilon}+\frac{\mathrm{S}^{*}}{\mathrm{~S}_{0}^{*}}\left[1-\frac{\varepsilon_{\mathrm{cr}}}{\varepsilon}\right] \\
\frac{\mathrm{W}_{\mathrm{e}}}{\mathrm{W}}=\frac{\mathrm{S}^{*}}{\mathrm{~S}_{0}^{*}}\left[1+\left(\frac{\mathrm{S}^{*}}{\mathrm{~S}_{0}^{*}}-1\right)\left(1-\frac{\mathrm{S}^{*}}{\mathrm{~S}_{0}^{*}}-\frac{\mathrm{P}}{\mathrm{P}_{\mathrm{cr}}}\right)^{-1}\right]
\end{gathered}
$$

where $P_{c r}$ is the buckling load, $\varepsilon_{c r}=\frac{\Delta_{c r}}{L} \quad$ is the average strain at buckling, and $\varepsilon=\frac{\Delta}{\mathrm{L}} \quad$ is the average strain in the plate for the load $\mathrm{P}$.

Compression-loaded plates with a centrally located cutout exhibit a reduction in their effective axial prebuckling stiffness and a redistribution of the internal loads toward the unloaded edges, as illustrated in Fig. 4. Moreover, this effect is amplified when a plate with a cutout buckles. Thus, it is possible to introduce an effective-width concept for plates with a cutout in both the prebuckling and postbuckling ranges by following the same rationale that has been presented above. The relationship between the axial stiffness of an unbuckled plate without a cutout, $S_{0}^{*}$, and the stiffnesses of an unbuckled and buckled plate with a cutout is illustrated in Fig. 5. In the prebuckling range, the effective-width ratio defined by Eq. (3) can be expressed by (see Fig. 5)

$$
\frac{W_{e}}{W}=\frac{S_{0}}{S_{0}^{*}}
$$

where $S_{0}$ is the prebuckling stiffness of the corresponding plate with a cutout. In the postbuckling range, the ratio of 
the effective width to the actual width for bilinear load versus end-shortening curves can be expressed in terms of the prebuckling stiffnesses $S_{0}^{*}$ and $S_{0}$ and the postbuckling stiffness $S$ of the corresponding plate with a cutout by either of the following equations

$$
\begin{gathered}
\frac{\mathrm{W}_{\mathrm{e}}}{\mathrm{W}}=\frac{\mathrm{S}_{0}}{\mathrm{~S}_{0}^{*}}\left[\frac{\varepsilon_{\mathrm{cr}}}{\varepsilon}+\frac{\mathrm{S}}{\mathrm{S}_{0}}\left(1-\frac{\varepsilon_{\mathrm{cr}}}{\varepsilon}\right)\right] \\
\frac{\mathrm{W}_{\mathrm{e}}}{\mathrm{W}}=\left(\frac{\mathrm{S}_{0}}{\mathrm{~S}_{0}^{*}}\right)\left(\frac{\mathrm{S}}{\mathrm{S}_{0}}\right)\left[1+\left(\frac{\mathrm{S}}{\mathrm{S}_{0}}-1\right)\left(1-\frac{\mathrm{S}}{\mathrm{S}_{0}}-\frac{\mathrm{P}}{\mathrm{P}_{\mathrm{cr}}}\right)^{-1}\right]
\end{gathered}
$$

\section{Finite-Element Model and Analyses}

Nonlinear finite-element analyses were conducted in the present study to provide insight into the experimental response trends that are subsequently presented herein. The plates were analyzed with the STAGS finite-element code. ${ }^{8}$ A typical finite-element model of a perfectly flat plate with a centrally located, circular cutout that was used in the study is illustrated in Fig. 6. Points on the plate mid-surface are located by an $x-y-z$ coordinate frame whose origin is at the top left corner of the plate. The plate length and width are defined as $\mathrm{L}$ and $\mathrm{W}_{\mathrm{a}}$, respectively, and the cutout diameter is denoted by $\mathrm{d}$. The nominal plate lengths and widths were $10.0 \mathrm{in}$. for all plates. Cutout diameters ranged from 0 to 6.6 in. Both aluminum and graphite-epoxy composite plates were considered in this study. The aluminum plates were made of 6061T6 alloy sheets and were modeled with a uniform, average measured thickness of $0.0647 \mathrm{in}$. The nominal material properties for 6061-T6 aluminum alloy are: Young's modulus $\mathrm{E}=$ $10.0 \times 10^{6} \mathrm{psi}$ and Poisson's ratio $v=0.33$. The laminatedcomposite plates were modeled by using a uniform thickness equal to the average measured plate thicknesses that are given in Table 1. All of the laminated-composite plate test specimens were made of Hercules, Inc. AS4/3502 graphite-epoxy material. The nominal lamina properties reported in Ref. 6 and used herein include a longitudinal modulus $\mathrm{E}_{1}=18.5 \times$ $10^{6} \mathrm{psi}$, a transverse modulus $\mathrm{E}_{2}=1.6 \times 10^{6} \mathrm{psi}$, an inplane shear modulus $\mathrm{G}_{12}=0.832 \times 10^{6} \mathrm{psi}$, and a major Poisson's ratio $v_{12}=0.35$.

Idealizations of the test-fixture support conditions were used in the finite-element model. To simulate clamped loaded edges, the out-of-plane displacements, $w$, and the tangential displacements, $v$, were set equal to zero in the boundary regions of the finite-element model that extend $1 / 4 \mathrm{in}$. from each loaded end of a plate (see Fig. 6). The compression load was introduced into the plate by applying a uniform end-displacement $\Delta$ to one end of the model while holding the other end of the panel fixed on the boundary, as illustrated in Fig. 6 ; that is, $\mathrm{u}(0, \mathrm{y})=\Delta$ and $\mathrm{u}(\mathrm{L}, \mathrm{y})=0$. The simply supported, unloaded edges (knife-edge supports) were simulated by setting the out-of-plane displacement equal to zero on a line $1 / 4$ in. from each unloaded edge of a panel. The corresponding unsupported width of the plate that is between the knife edges is given by $W=9.5 \mathrm{in}$. The tangential displacements, $\mathrm{u}$, were unrestrained on the unloaded edges. In addition, the unloaded edges are free to translate in the y-coordinate direction.

The finite-element meshes used in the present study were defined by using user-written subroutines that are compatible with the STAGS finite-element code. ${ }^{8}$ These userwritten subroutines facilitated the generation of models with different cutout sizes and mesh densities, and provided a convenient means for assessing the convergence of a given finiteelement model. Convergence studies were done for all finiteelement models and a typical converged finite-element mesh is shown in Fig. 6. The models consist of four-noded STAGS 410 quadrilateral shell elements. The 410 element is a flat, facet-type element that is based on the Kirchoff-Love shell hypotheses and the nonlinear Lagrangian strain tensor. The element nodes include three drilling degrees of freedom and three translational degrees of freedom. Large rotations are accounted for at the element level by the use of a corotational algorithm. The element theory is documented in Ref. 8.

The STAGS code uses both the modified and full Newton methods for its nonlinear solution algorithms. The STAGS equivalence transformation (ET) processor is used to continue beyond bifurcation points into the postbuckling response range of a solution. The ET processor allows the user to select a solution branch in the direction of growth of a bifurcation mode that has been computed for the nonlinear stress state in the neighborhood of the bifurcation point. This bifurcation mode is held constant, with a magnitude specified by the user, and the load factor in the solution is adjusted until the solution residual vanishes.

The prebuckling responses of the plates considered herein were determined by using the geometrically nonlinear, quasi-static analysis capability in STAGS. The ET processor was used to get beyond the bifurcation point and branch onto the postbuckling equilibrium path of the panels. Once the initial postbuckling path was established for a plate, the analysis was continued into the postbuckling response range by using the quasi-static analysis algorithm in STAGS. A typical finite-element model contained approximately 10,000 degrees of freedom.

The initial prebuckling stiffnesses of the geometrically perfect, idealized test specimens were obtained by computing the slope of a line passing through two solution points on the primary branch of the load versus end-shortening curve. Similarly, the initial postbuckling stiffnesses were obtained by computing the slope of the line that passes through the bifurcation point on the load versus end-shortening curve for a given specimen and that is tangent to the stable secondary equilibrium path.

Nonlinear finite-element analyses of geometrically 
imperfect plates were also conducted in the present study primarily to determine the effect of initial geometric imperfections on the prebuckling stiffness of a plate and because initial geometric imperfections are known to affect the effective width of a compression-loaded plate. ${ }^{10}$ Because no full-field or other type of initial imperfection measurement data are available, an eigen-mode imperfection characterized by a single half-wave shape along the coordinate axes and a variable amplitude was used. For these geometrically imperfect plates, the prebuckling stiffnesses were obtained in the same manner as described previously for the geometrically perfect plates.

\section{Results and Discussion}

The experimental results presented in Refs. 6 and 7 for square aluminum plates and for square $\left[0_{10}\right]_{\mathrm{s}},\left[90_{10}\right]_{\mathrm{s}},[(0 /$ $\left.90)_{5}\right]_{s},\left[( \pm 30)_{6}\right]_{s},\left[( \pm 45)_{6}\right]_{s}$, and $\left[( \pm 60)_{6}\right]_{s}$ laminated-composite plates with or without a central circular cutout and subjected to a uniform axial edge displacement are described in this section. For these results, the compression-loaded edges of the plates were clamped in a test fixture and the unloaded edges were supported by knife edges, which are intended to simulate simply supported edges. The distance between the knife edges is the unsupported width of a plate and is designated herein by the symbol $\mathrm{W}$, and the relative size of the cutout is indicated by the ratio $\mathrm{d} / \mathrm{W}$. The nominal value of $\mathrm{W}$ is $9.5 \mathrm{in}$. for each specimen and the actual, nominal plate width $\mathrm{W}_{\mathrm{a}}$ is 10.0 in. Specific details about the test specimens and apparatus and details about the test procedure are described in Refs. 6 and 7 and are not repeated, for the most part, herein. All of the laminated-composite plates were made of Hercules, Inc. AS4/3502 graphite-epoxy material and the aluminum plates were made of 6061-T6 aluminum alloy material. The nominal material properties have been described in the previous section of the present paper.

First, the experimental results of Refs. 6 and 7 are presented in a manner that illustrates the effect of cutout size on the prebuckling and postbuckling axial stiffnesses of the aluminum plates and the laminated-composite plates. Because these experimental results exhibit some unusual trends, corresponding results that were obtained from nonlinear finite-element analyses are also presented to provide insight into the behavior. These finite-element analysis results are based on idealized geometry, boundary conditions, and loading conditions; uniform thickness distributions; and the nominal material properties that were previously described. Because of these idealizations and approximations, the finite-element analysis results are not intended to be used for test-analysis correlation. The finite-element results are used to provide a means for contrasting the behavioral trends from idealized analyses that a designer might use with the behavior that may exist in real structures. Next, effective widths are presented for selected experimental results as a function of the average axial-strain level to demonstrate the effects of laminate construction and cutout size. Finally, a compact design chart is presented that provides a means for representing effective widths of plates with or without a cutout in a general manner. Additional charts, based on finite-element analyses, that illustrate the effects of plate geometry and material properties on the parameters that appear in the compact design chart are also presented.

\section{Overall Stiffness Trends}

The test results of Refs. 6 and 7 are presented together in Figs. 7-9, and the corresponding analysis results are presented in Figs. 10-12. Graphs of the prebuckling stiffness ratio $S / S_{0}^{*}$, the postbuckling stiffness ratio $S / S^{*}$, and the postbuckling-to-prebuckling stiffness ratio $\mathrm{S} / \mathrm{S}_{0}$ that were measured experimentally are presented in Figs. 7-9, respectively. In Fig. $7, \mathrm{~S}_{0}^{*}$ is the experimentally measured prebuckling stiffness of the specimen without a cutout for each family of test specimens. In Fig. 8, $\mathrm{S} *$ is the experimentally measured postbuckling stiffness of the specimen without a cutout for each family of test specimens (values of $S_{0}^{*}$ and $S^{*}$ are given in Refs. 6 and 7). Corresponding graphs of the prebuckling stiffness ratio $S / S_{0}^{*}$, the postbuckling stiffness ratio $S / S^{*}$, and the postbuckling-to-prebuckling stiffness ratio $S / S_{0}$ that were obtained from finite-element analyses are presented in Figs. 10-12, respectively. In Fig. 10, $\mathrm{S}_{0}^{*}=\mathrm{E}_{\mathrm{x}} \mathrm{h}$ for each family of plates, and in Fig. $11, \mathrm{~S}^{*}$ is the postbuckling stiffness of the plate without a cutout that was obtained from the finite-element analyses for each family of plates. Values of $E_{x}$ for each of the laminates without a cutout and their average thicknesses $h$ are given in Table 1 . In all of these figures, results for the aluminum plates are given by the black line with the filled black circles. Similarly, results for the $\left[0_{10}\right]_{s},\left[90_{10}\right]_{s}$, and $\left[(0 / 90)_{5}\right]_{s}$ plates are given by the solid gray lines with the unfilled triangles, unfilled diamonds, and unfilled circles, respectively. Results for the $\left[( \pm 30)_{6}\right]_{s},\left[( \pm 45)_{6}\right]_{s}$, and $\left[( \pm 60)_{6}\right]_{s}$ plates are given by the dashed black lines with the unfilled triangles, unfilled diamonds, and unfilled squares, respectively.

The results in Fig. 7 generally show that the largest reductions in prebuckling stiffness with increasing cutout size are exhibited by the $\left[0_{10}\right]_{s}$ specimens, followed by the $[(0 /$ 90) $\left.{ }_{5}\right]_{\mathrm{s}}$ specimens. This trend is also exhibited by the finiteelement analysis results for the corresponding idealized plates (Fig. 10). The smallest reductions in prebuckling stiffness with cutout size are generally exhibited by the $\left[90_{10}\right]_{\mathrm{s}}$ specimens, followed by the $\left[( \pm 30)_{6}\right]_{\mathrm{s}}$ specimens. The finite-element analysis results of the corresponding idealized plates show that the smallest reductions in prebuckling stiffness with cutout size are exhibited by the $\left[( \pm 60)_{6}\right]_{5}$ specimens, followed by the $\left[( \pm 45)_{6}\right]_{s}$ specimens. However, only three data points are given for the specimens for values 
of $\mathrm{d} / \mathrm{W}$ up to 0.32 , and these data points are very close to the data points for the $\left[90_{10}\right]_{\mathrm{s}}$ and $\left[( \pm 30)_{6}\right]_{\mathrm{s}}$ specimens, which show the next smallest reductions in prebuckling stiffness with cutout size.

The results in Fig. 8 shows that all of the test specimens, except the $\left[90_{10}\right]_{\mathrm{s}}$ specimens, exhibit a reduction in postbuckling stiffness with increasing cutout size. A somewhat similar trend is exhibited in Fig. 11 by the analysis results. The $\left[(0 / 90)_{5}\right]_{\mathrm{s}}$ specimens generally exhibit the largest, smooth reduction in the postbuckling stiffness with cutout size, followed closely by the aluminum specimens. In contrast, the $\left[90_{10}\right]_{\mathrm{s}}$ test specimens with $\mathrm{d} / \mathrm{W}=0.21,0.32$, and 0.42 exhibit postbuckling stiffnesses between $25 \%$ and $56 \%$ greater than the postbuckling stiffness of the corresponding plate without a cutout. Similarly, the corresponding analysis results in Fig. 11 for the $\left[90_{10}\right]_{\mathrm{s}}$ plates show a marked increase in $\mathrm{S} / \mathrm{S}^{*}$ as $\mathrm{d} / \mathrm{W}$ increases to 0.11 followed by a very substantial reduction. The smallest reductions in postbuckling stiffness with cutout size shown in Fig. 8 are generally exhibited by the $\left[( \pm 30)_{6}\right]_{s}$ specimens, followed by the $\left[0_{10}\right]_{s}$ specimens. In Fig. 11, the analysis results show that the smallest reductions in postbuckling stiffness with cutout size are generally exhibited by the $\left[( \pm 30)_{6}\right]_{s}$ plates.

Although many of the test specimens exhibit a reduction in postbuckling stiffness with increasing cutout size (see Fig.8), none of the specimens show a significant reduction in the ratio of the initial postbuckling stiffness to the prebuckling stiffness, $\mathrm{S} / \mathrm{S}_{0}$ (see Fig.9). This trend is also exhibited by the finite-element analysis results shown in Fig. 12 for the corresponding idealized plates, which initially appears to be nonintuitive. The trend is explained by observing that the prebuckling and postbuckling stiffnesses of these plates are changing approximately the same rate as the cutout size increase; that is, the slopes of the corresponding curves in the figures are approximately the same.

The $\left[0_{10}\right]_{\mathrm{s}}$ and $\left[( \pm 30)_{6}\right]_{\mathrm{s}}$ specimens exhibit the smallest values of $\mathrm{S} / \mathrm{S}_{0}$ and show the largest increases with increasing cutout size, which means that the prebuckling stiffness of these plates is generally decreasing faster with increasing cutout size than the postbuckling stiffness. The analysis results for the corresponding idealized plates show that the $\left[0_{10}\right]_{\mathrm{s}}$ and $\left[(0 / 90)_{5}\right]_{\mathrm{s}}$ specimens generally exhibit the smallest values of $S / S_{0}$ and show the largest increases with increasing cutout size, followed by the $\left[( \pm 30)_{6}\right]_{\mathrm{s}}$ specimens. Many of the test specimens show little change in the value of $\mathrm{S} / \mathrm{S}_{0}$ with increasing cutout size, particularly for $\mathrm{d} / \mathrm{W}>$ 0.1 . This trend is also exhibited by the finite-element analysis results for the corresponding idealized plates. The overall largest values of $S / S_{0}$ are generally exhibited by the aluminum, $\left[( \pm 60)_{6}\right]_{\mathrm{s}}$ and $\left[(0 / 90)_{5}\right]_{\mathrm{s}}$ specimens. The corresponding results for the idealized plates predict that the overall largest values of $S / S_{0}$ are exhibited by the $\left[( \pm 60)_{6}\right]_{s}$ and $\left[(90)_{10}\right]_{\mathrm{s}}$ plates. In nearly every case, the values of $S /$
$\mathrm{S}_{0}$ for test specimens with a cutout are greater than the corresponding value for a plate without a cutout. This effect is most pronounced for the $\left[90_{10}\right]_{\mathrm{s}}$ specimens and is also predicted by the analysis results. This trend, and the nonintuitive behavior of the $\left[90_{10}\right]_{\mathrm{s}}$ specimens, is also exhibited to a large extent by the analysis results shown in Fig. 12.

The test results in Figs. 7-9 include real effects like initial geometric imperfections, residual stresses, loading and thickness nonuniformities, and non-ideal support conditions that are likely to be encountered in real structures. This fact accounts, to a large extent, for the differences between the corresponding test results and the idealized finite-element analysis results that are shown in the figures. In addition, the experimentally measured values of the initial postbuckling stiffnesses are, to some degree, subjective and contribute to the differences between test and analysis results. In particular, the prebuckling and initial postbuckling results obtained from the finite-element analyses are obtained in a well-defined manner that has been described previously herein. Similarly, the prebuckling stiffnesses of the test specimens in Refs. 6 and 7 were obtained by determining the slope of the initial linear branch of the load versus endshortening curve, which is also a relatively well-defined process. In contrast, the postbuckling stiffnesses of the test specimens in Refs. 6 and 7 were obtained by fitting a line to the linear-most portion of the secondary branch of the load versus end-shortening curve and finding the slope, which does not necessarily yield a unique result when initial imperfections are present. This process, which was used in Refs. 6 and 7, was also guided by other data that were recorded during the tests.

One significant cause of the differences between the test and analysis results appears to be initial geometric imperfections (deviation from flatness). The effects of an initial geometric imperfection on the normalized prebuckling stiffness $\mathrm{S}_{0} / \mathrm{E}_{\mathrm{x}} \mathrm{h}$ of aluminum plates and $\left[0_{10}\right]_{\mathrm{s}}$ and $\left[90_{10}\right]_{\mathrm{s}}$ graphite-epoxy plates without a cutout, that were obtained from finite-element analyses $\left(\mathrm{E}_{\mathrm{x}}=\mathrm{E}\right.$ for aluminum plates), are shown in Fig. 13. For these results, an initial imperfection in the form of a half-sine wave along each coordinate direction and amplitude-to-average-plate-thickness ratio $\mathrm{A} /$ $\mathrm{h}$ was used because no measured imperfection data was available. The results in Fig. 13 indicate a similar reduction in axial prebuckling stiffness for all three plates as $\mathrm{A} / \mathrm{h}$ increases, with a maximum reduction of approximately $33 \%$ for an imperfection amplitude equal to the average plate thickness, $h(A / h=1)$. Thus, it is very likely that the discrepancies between the analysis and test results curves for $\mathrm{S}_{0} /$ Eh in Fig. 7 are caused, to some extent, by initial geometric imperfections. This observation is consistent with the results presented in Ref. 10 that show a significant effect of initial geometric imperfections on the effective width of metallic plates. Moreover, the corresponding load versus outof-plane deflection curves presented in Refs. 6 and 7 indicate that relatively large initial geometric imperfections may 
have been present in many of the test specimens. Other sources of discrepancies between the finite-element analysis and experimental results are variations in thickness and material properties, residual stresses, and nonuniform load introduction effects that were not measured for the test specimens. In addition, the idealization of the actual boundary conditions provided by the test fixture is likely to contribute some difference between the test and analysis results.

Regardless of the differences between corresponding test and analysis results presented in Figs. 7 through 12, both the test and analysis results predict several of the same trends. Most importantly, the test and analysis results indicate a complex interaction between plate orthotropy and cutout size which results in significant variations in the prebuckling and postbuckling stiffness ratios of compression-loaded plates with or without a cutout. The result also show that real, imperfection-like effects can greatly affect the behavior of plates and should be considered in their design.

\section{Effective-Width Ratios}

Plots of effective-width ratios provide a simple means for incorporating the postbuckling strength and stiffness of plate subcomponents into the design of stiffened structures. Similarly, as shown previously herein, effective-width ratios can be defined for structural details, like a cutout, that cause a similar load redistribution as the structural detail increases in influence. In this section, effective-width ratios $\frac{W_{e}}{W}$ are presented as a function of normalized strain $\frac{\varepsilon}{\varepsilon_{c r}}$ for the aluminum test specimens and the $\left[0_{10}\right]_{\mathrm{s}},\left[90_{10}\right]_{\mathrm{s}},[(0 /$ $\left.90)_{5}\right]_{\mathrm{s}}$, and $\left[( \pm 30)_{6}\right]_{\mathrm{s}}$ laminated-composite test specimens considered herein in Figs. 14-18, respectively. In particular, prebuckling and postbuckling effective-width ratios are presented for $\mathrm{d} / \mathrm{W}$ values that range from $\mathrm{d} / \mathrm{W}=0.0$ to $\mathrm{d} /$ $\mathrm{W}=0.66$ and implicitly include real imperfections like initial geometric imperfections and thickness nonuniformities. The prebuckling range of the figures corresponds to $\frac{\varepsilon}{\varepsilon_{\mathrm{cr}}}<$ 1. Similar plots can be generated for the finite-element analysis results that have been presented herein, but have been omitted in favor of the compact design curve that is presented in Fig. 19. The effective widths in Figs. 14-18 are determined by using Eq. (7) and the inputs used in Eq. (7) are from the experimentally measured results that were presented in the previous section. As a result of using Eq. (7), the effective-width curves that are presented subsequently are based on a bilinear representation of the load versus endshortening curves, and represent the initial postbuckling behavior of the test specimens. Material nonlinearities and large geometric nonlinearities that are associated with deviations from a bilinear load-end-shortening curve are not considered in the present study.

The test results shown in Figs. 14-18 exhibit many of the same general trends. For example, the results indicate that the effective widths of the plates are constant in the prebuckling response range, as expected. In addition, with the exception of the results for the $\left[90_{10}\right]_{\mathrm{s}}$ specimens, the results indicate that, as $\mathrm{d} / \mathrm{W}$ increases, the prebuckling effective width decreases monotonically. Moreover, in the postbuckling response range, the effective widths of the plates generally decrease monotonically with increasing strain level for all cutout sizes. The test results for the $\left[90_{10}\right]_{\mathrm{s}}$ specimens that are presented in Fig. 16 indicate that the prebuckling effective width of the plate with $\mathrm{d} / \mathrm{W}=0.42$ is approximately $16 \%$ greater than the prebuckling effective width of the corresponding plate without a cutout. In the postbuckling response range, the effective widths of the $\left[90_{10}\right]_{\mathrm{s}}$ specimens decrease monotonically with $\frac{\varepsilon}{\varepsilon_{\mathrm{cr}}}$. However, the results indicate that the $\left[90_{10}\right]_{\mathrm{s}}$ specimen with a larger cutout does not correspond to lower effective-width ratios. More specifically, the results show that, for values of $\frac{\varepsilon}{\varepsilon_{\mathrm{cr}}}$ slightly greater than 1 , the $\left[90_{10}\right]_{s}$ specimens with small values of $d / W$ have higher effective-width ratios than the specimens with larger values of $d / W$. However, for larger values of $\frac{\varepsilon}{\varepsilon_{c r}}$ this trend is reversed, and the $\left[90_{10}\right]_{\mathrm{s}}$ specimens with larger values of $\mathrm{d} / \mathrm{W}$ exhibit larger effective-width ratios than the specimens with smaller values of $d / W$. Like the results presented in the previous section, the results in Figs. 14-18 indicate a complex interaction between plate orthotropy and cutout size which results in significant variations in the prebuckling and postbuckling effective-width ratios of compression-loaded plates with or without cutouts.

Equation (7) forms the basis for a very compact or concise way of representing the effective widths of the general class of laminated plates in addition to metallic plates. This property of $\mathrm{Eq}$. (7) results from the fact that it applies to compression-loaded plates, with or without a cutout, and can be used with measured test data for $S / S_{0}^{*}$ and $S / S_{0}$ or data from analytical or numerical methods. Similarities and differences in the behavior of various plates can be highlighted and compared directly by casting Eq. (7) into the form of a generic design chart like the one shown in Fig. 19. In this figure, stiffness-weighted, effective-width ratios are presented as a function of normalized strain for values of $\mathrm{S} /$ $\mathrm{S}_{\mathrm{o}}=.1, .2, .3, .4, .5, .6, .7$, and .8 . Insight into response trends can be obtained by generating results such as those presented in Figs. 7 and 9 for the test specimens considered herein or such as the finite-element analysis results presented in Figs. 10 and 12.

\section{Extrapolation of the Results}

The concept of effective width can be applied to any structural detail or discontinuity that affects the apparent axial stiffness of a plate and causes the stresses on the loaded 
edges of a compression-loaded plate to be redistributed toward the unloaded edges. For example, load introduction and thickness nonuniformities, initial geometric imperfections, spatial variation in material properties, boundary conditions, residual stresses, and certain kinds of damage affect the stiffness ratios $S / S_{0}^{*}$ and $S / S_{0}$, and graphs that show these effects can be used with Eq. (7) and Fig. 19 to obtain values for the effective width and the corresponding behavioral trends caused by variations in the stiffness parameters. A specific example of how the results presented herein can be used is given by a damage state in a plate that does not propagate or grow significantly with the load level. For this case, the load versus end-shortening response curve can be approximated by a bilinear curve and the effect of the damage on the stiffness ratios $S / S_{0}^{*}$ and $S / S_{0}$ can be replaced by an estimated equivalent (or conservative) cutout. More precise values for the effective width could be obtained by establishing experimentally the effect of damage on the stiffness ratios $S / S_{0}^{*}$ and $S / S_{0}$.

The approach presented herein should not be used for extensive damage propagation with load, material nonlinearities, geometric nonlinearities, or any other quantity that results in load versus end-shortening response curves that cannot be approximated as bilinear curves. However, Eq. (2) forms the basis for defining an effective width for laminated-composite plates, just as it did for yielding in metallic plates. ${ }^{11}$ For this type of behavior, $\left(\mathrm{N}_{\mathrm{x}}\right)_{\max }$ in Eq. (2) must be related to the applied end-shortening by a failure criterion, such as the maximum strain criterion.

\section{Concluding Remarks}

A study of the effects of cutouts and laminate construction on the prebuckling and initial postbuckling stiffnesses and the corresponding effective widths of compressionloaded, symmetrically laminated-composite and aluminum square plates has been presented. The effective-width concept has been extended to plates with cutouts, and results have been presented that include previously published experimental results and nonlinear finite-element analysis results for the corresponding geometrically perfect plates with idealized support and loading conditions and material properties. Behavioral trends that were obtained from the experimental results and from finite-element analysis results have been presented and compared for seven plate families and cutout diameter-to-plate width ratios ranging from 0 to 0.66 . In addition, a general, compact design curve that can be used to determine and compare the effective widths of a wide range of laminated-composite plate constructions has been presented, and a discussion of how the results can be used and extended to include certain types of centralized damage, cracks, and other structural discontinuities or details that affect the axial stiffness of a plate has been given.

The results show that some plates with cutouts can have significantly higher prebuckling and initial postbuckling stiffnesses and effective widths than the corresponding plate without a cutout. These results illustrate a complex interaction between cutout size and plate membrane and bending orthotropies that affect the internal load distribution in a plate.

\section{References}

1. Von Kármán, T., Sechler, E. E., and Donnell, L. H., "The Strength of Thin Plates in Compression," ASME Transactions, APM-54-5, Vol. 54, No. 2, January 30, 1932, pp. 53-57.

2. Bengston, H. W., "Ship Plating Under Compression and Hydro static Pressure," presented at the annual meeting of the Society of Naval Architects and Marine Engineers, New York, NY, November 16-17, 1939, Paper No. 1.

3. Steinbacher, F. R. and Gerard, G., Aircraft Structural Mechanics, Pitman Publishing Corp., 1952, pp. 289-294.

4. Hu, P. C., Lundquist, E. E., and Batdorf, S. B., "Effect of Small Deviations From Flatness on Effective Width and Buckling of Plates in Compression," NACA Technical Note No. 1124, September 1946.

5. Nemeth, M. P., "Buckling and Postbuckling Behavior of Laminated Composite Plates With a Cutout," NASA Technical Paper 3587, July 1996.

6. Nemeth, M. P., "Buckling and Postbuckling Behavior of Square Compression-Loaded Graphite-Epoxy Plates With Circular Cutouts," NASA Technical Paper 3007, August 1990.

7. Nemeth, M. P., "Buckling and Postbuckling Behavior of Compression-Loaded Isotropic Plates With Cutouts," NASA Technical Paper 3024, September 1990.

8. Rankin, C. C., Brogan, F. A., Loden, W. A. and Cabiness, H. D., STAGS Users Manual, Lockheed Palo Alto Research Laboratory, Report LMMS P032594, 1999.

9. Dym, C. L., Stability Theory and Its Applications to Structural Mechanics, Noordhoff-International, Leyden, The Netherlands, 1974.

10. Vilnay, O. and Rockey, K. C., "A Generalized Effective Width Method for Plates Loaded in Compression," J. Constructional Steel Research, Vol. 1, No. 3, 1981, pp. 3-12.

11. Mayers, J. and Budiansky, B., "Analysis and Behavior of Simply Supported Flat Plates Compressed Beyond the Buckling Load into the Plastic Range," NACA Technical Note No. 3368, February 1955. 
Table 1: Apparent axial modulus and average thickness of geometrically perfect plates considered in the present study.

\begin{tabular}{|c|c|c|}
\hline Plate type & $\begin{array}{c}\text { Apparent axial } \\
\text { modulus, } \mathrm{E}_{\mathrm{x}}(\mathrm{Msi})\end{array}$ & $\begin{array}{c}\text { Average thickness, } \mathrm{h} \\
\text { (in.) }\end{array}$ \\
\hline \hline Aluminum & 10.00 & 0.0647 \\
\hline$\left[(0)_{10}\right]_{\mathrm{s}}$ & 18.50 & 0.1100 \\
\hline$\left[(90)_{10}\right]_{\mathrm{s}}$ & 1.60 & 0.1100 \\
\hline$\left[(0 / 90)_{5}\right]_{\mathrm{s}}$ & 10.13 & 0.1100 \\
\hline$\left[( \pm 30)_{6}\right]_{\mathrm{s}}$ & 7.16 & 0.1176 \\
\hline$\left[( \pm 45)_{6}\right]_{\mathrm{s}}$ & 2.88 & 0.1300 \\
\hline$\left[( \pm 60)_{6}\right]_{\mathrm{s}}$ & 1.82 & 0.1176 \\
\hline
\end{tabular}




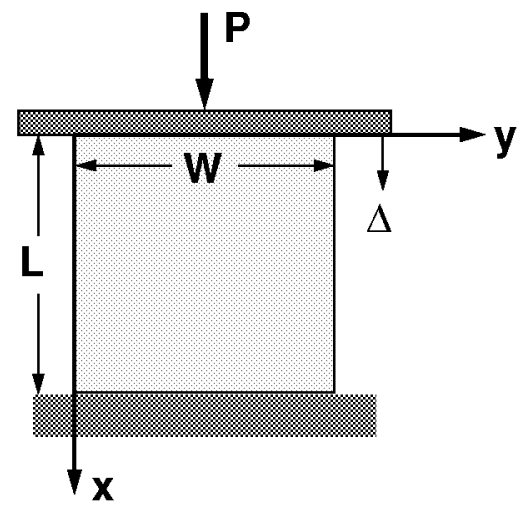

(a) Plate configuration and coordinate system

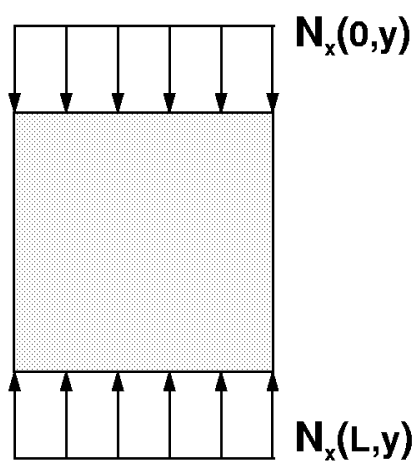

(c) Stress resultant distribution at loaded edges for $\mathrm{P}<\mathrm{P}_{\mathrm{cr}}$

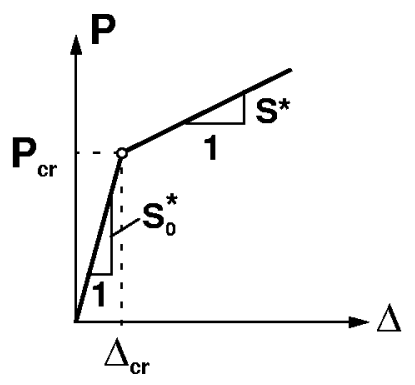

(b) Bilinear load versus end-shortening diagram

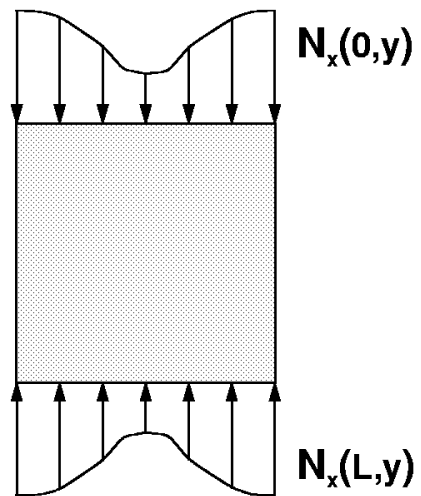

(d) Stress resultant distribution at loaded edges for $\mathrm{P}>\mathrm{P}_{\text {cr }}$

Fig. 1 Coordinate system, loading condition, response diagram, and axial stress resultant distribution in square plates without a cutout. 


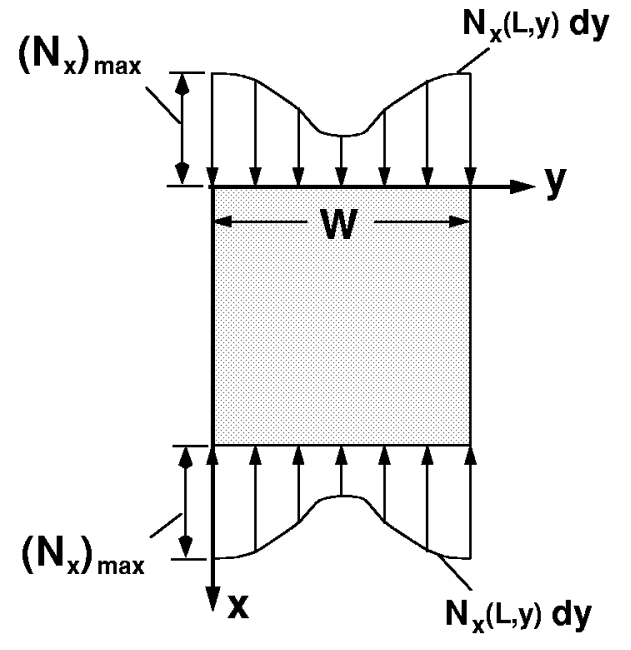

(a) Axial stress resultant distribution at loaded edges for $\mathrm{P}>\mathrm{P}_{\text {cr }}$
$\left(\mathbf{N}_{\mathrm{x}}\right)_{\max }$

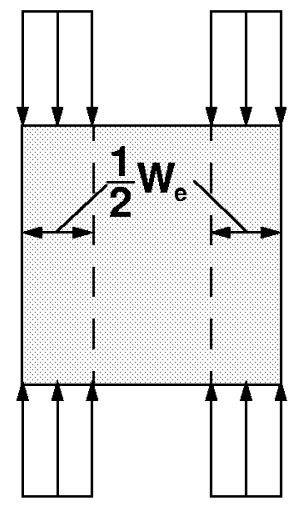

$\left(N_{x}\right)_{\max }$

(b) Stress resultant acting over effective width, $\mathrm{W}_{\mathrm{e}}$

Fig. 2 Stress resultant distribution, average stress result distribution, and effective width for square plates without a cutout.

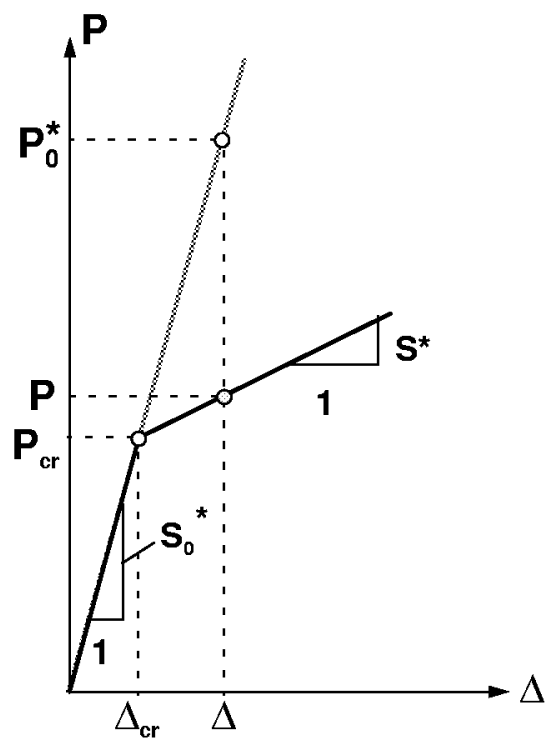

Fig. 3 Bilinear load versus end-shortening diagrams used to compute the effective widths of plates without a cutout. 


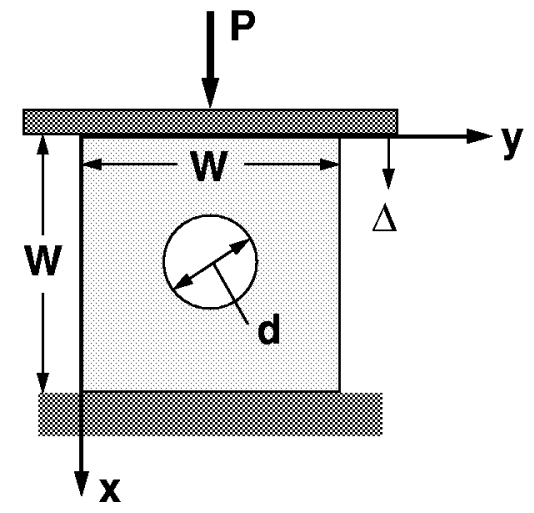

(a) Unloaded plate with a cutout and the coordinate system

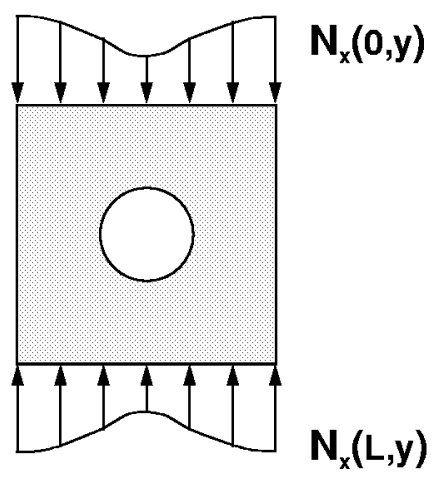

(c) Stress resultant distribution at loaded edges for $\mathrm{P}<\mathrm{P}_{\text {cr }}$

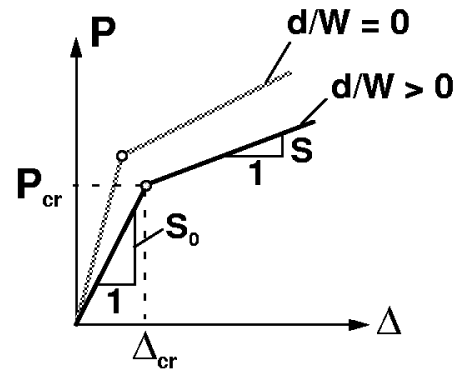

(b) Bilinear load versus end-shortening diagram

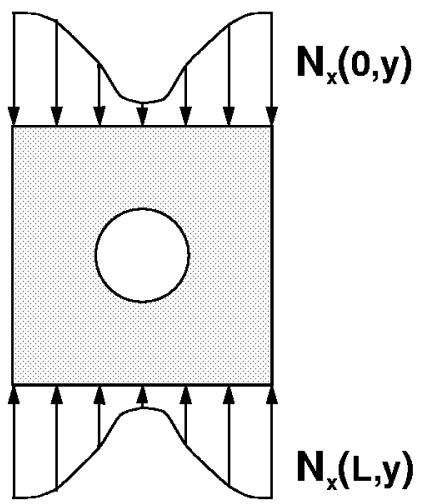

(d) Stress resultant distribution at loaded edges for $\mathrm{P}>\mathrm{P}_{c r}$

Fig. 4 Coordinate system, loading condition, response diagram, and axial stress resultant distribution in square plates with a cutout. 


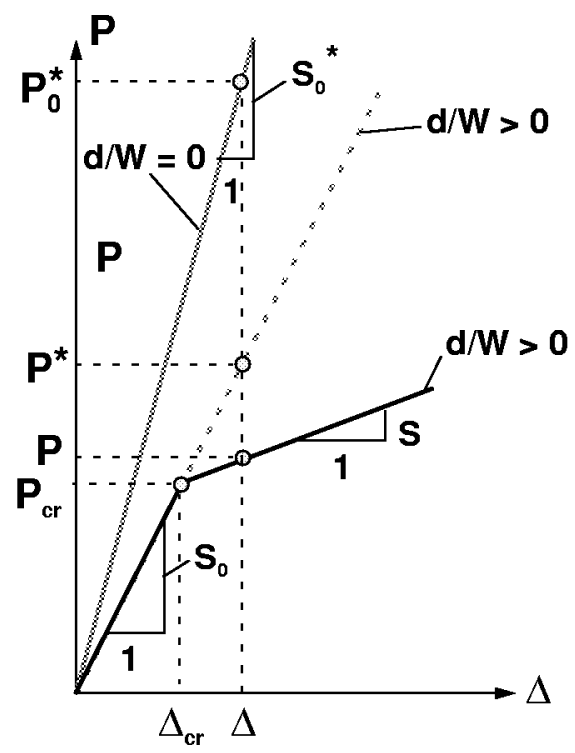

Fig. 5 Bilinear load versus end-shortening diagram used to compute the effective width of a plate with a cutout.

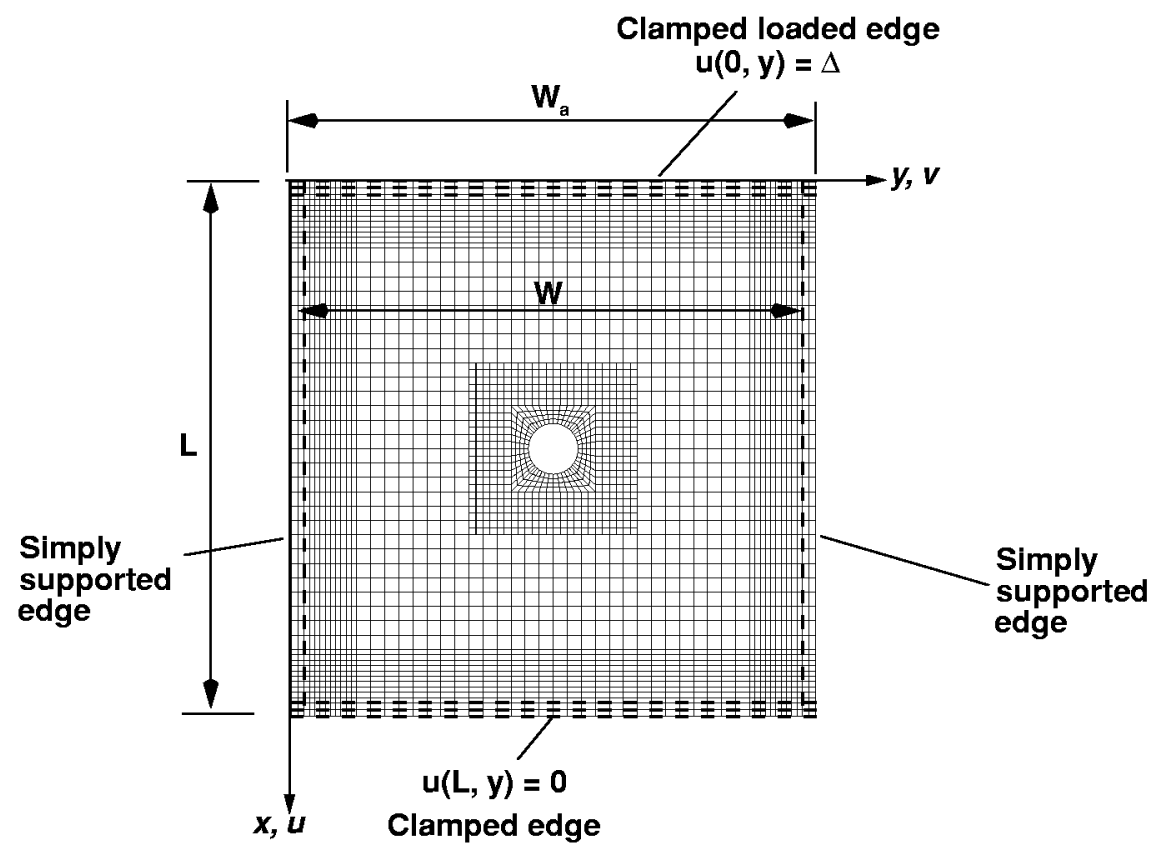

Fig. 6 Typical finite-element model geometry and boundary conditions (dashed lines mark the rows on which the out-of-plane boundary conditions are applied). 


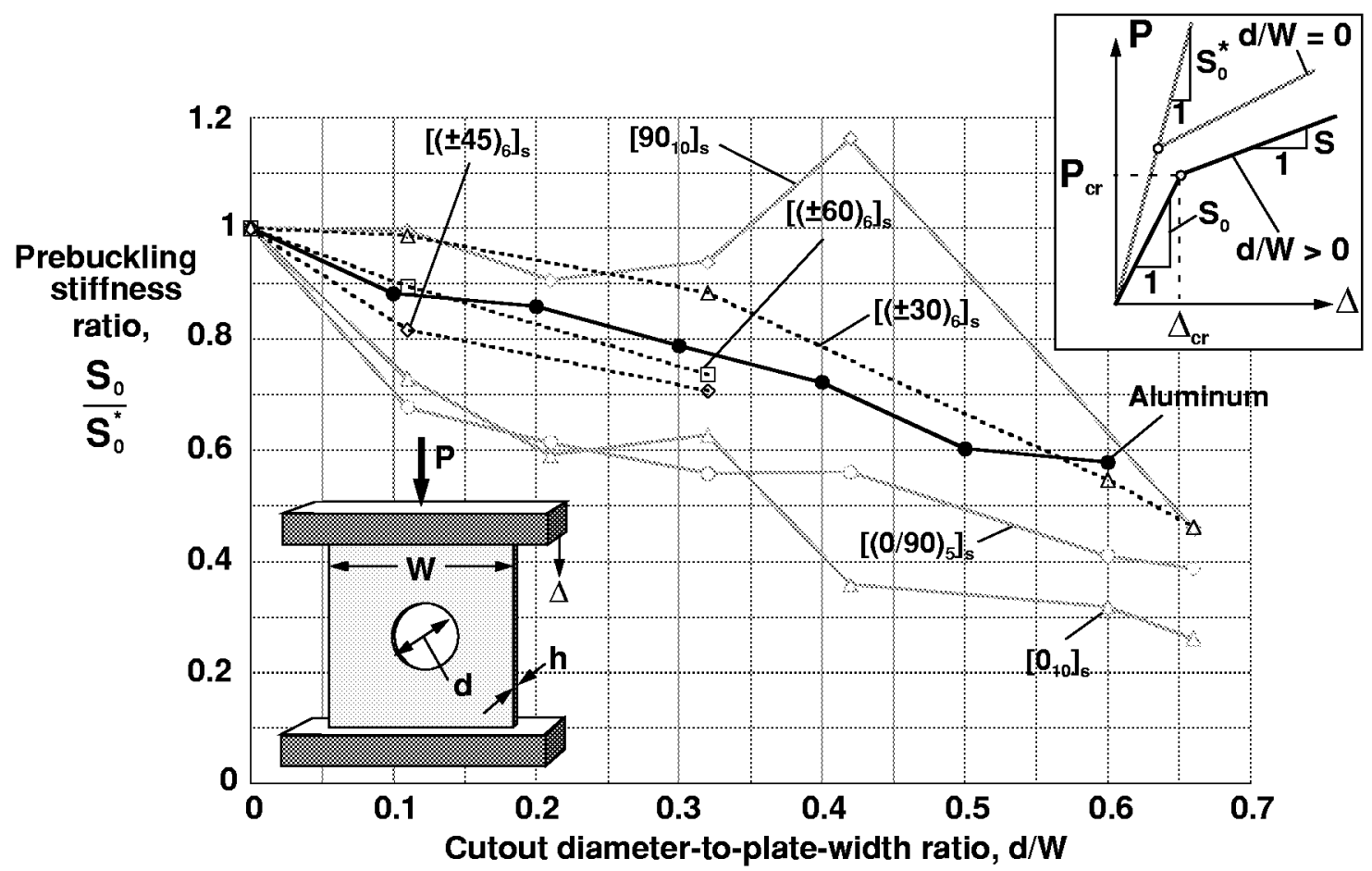

Fig. 7 Prebuckling stiffness ratios for square aluminum and laminated-composite plates, with and without a central circular cutout, obtained from experiments.

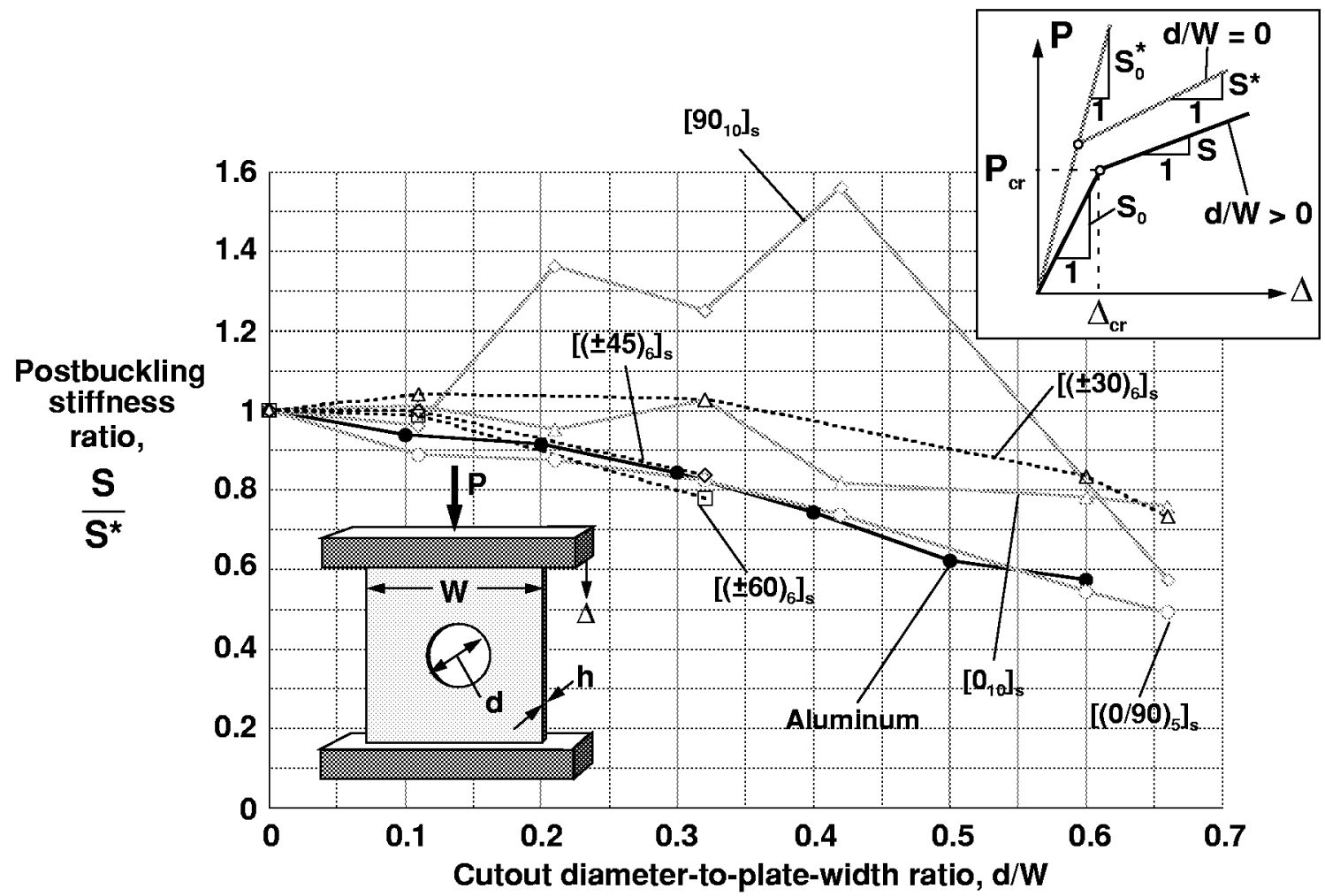

Fig. 8 Postbuckling stiffness ratios for square aluminum and laminated-composite plates, with and without a central circular cutout, obtained from experiments. 


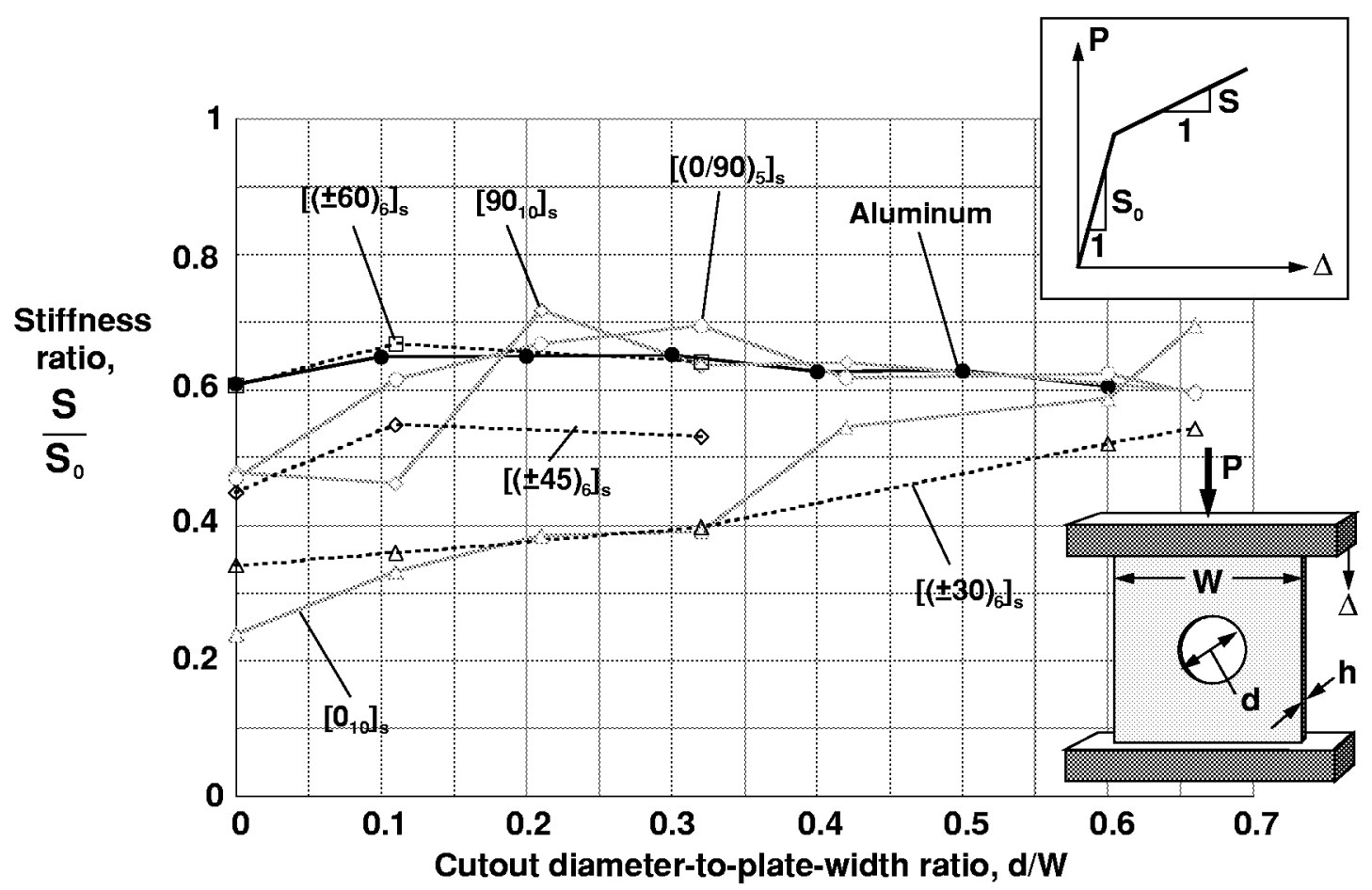

Fig. 9 Postbuckling-to-prebuckling stiffness ratios for square aluminum and laminated-composite plates, with and without a central circular cutout, obtained from experiments.

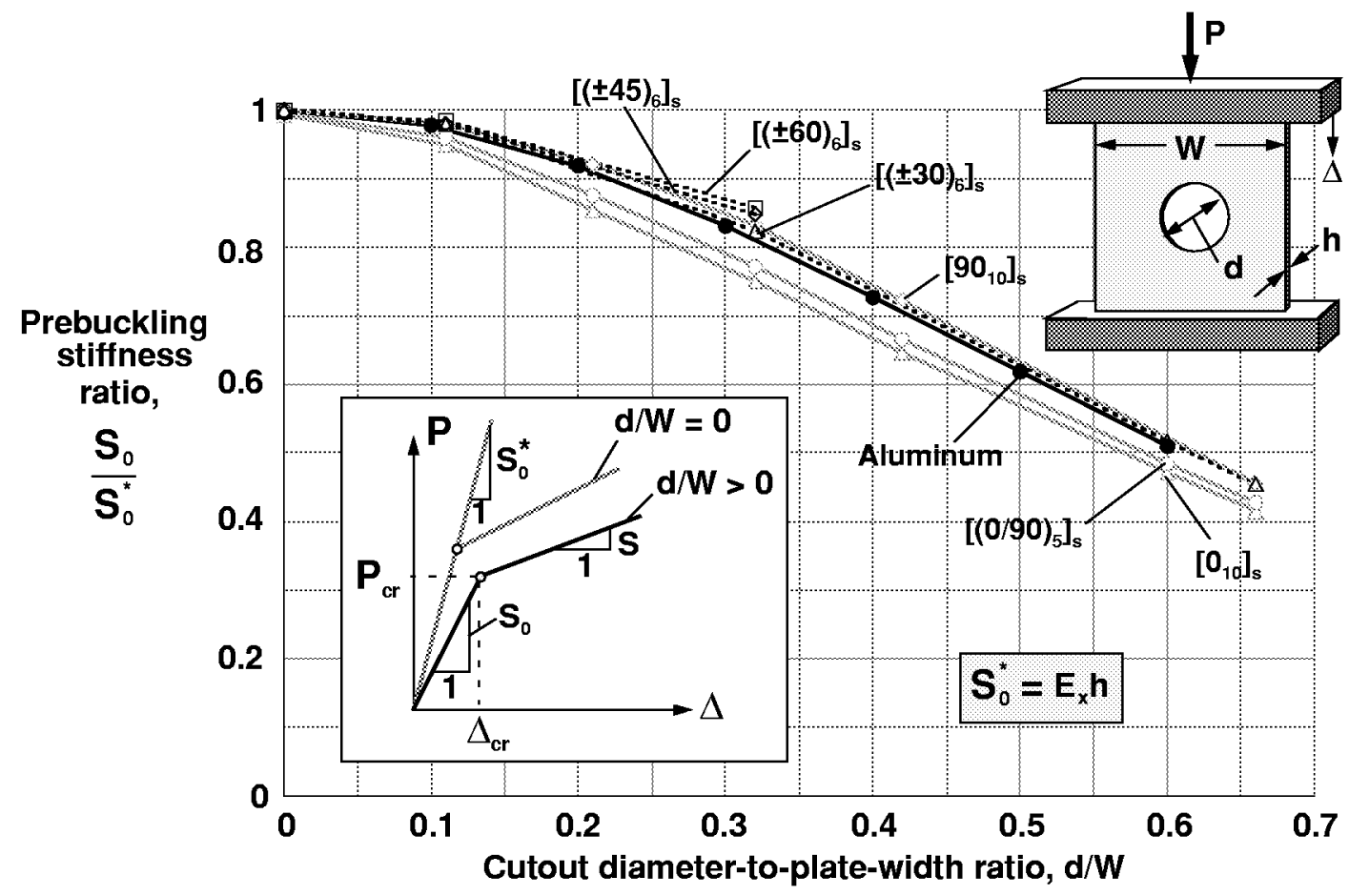

Fig. 10 Prebuckling stiffness ratios for perfectly flat, square aluminum and laminated-composite plates, with and without a central circular cutout, obtained from finite-element analyses. 


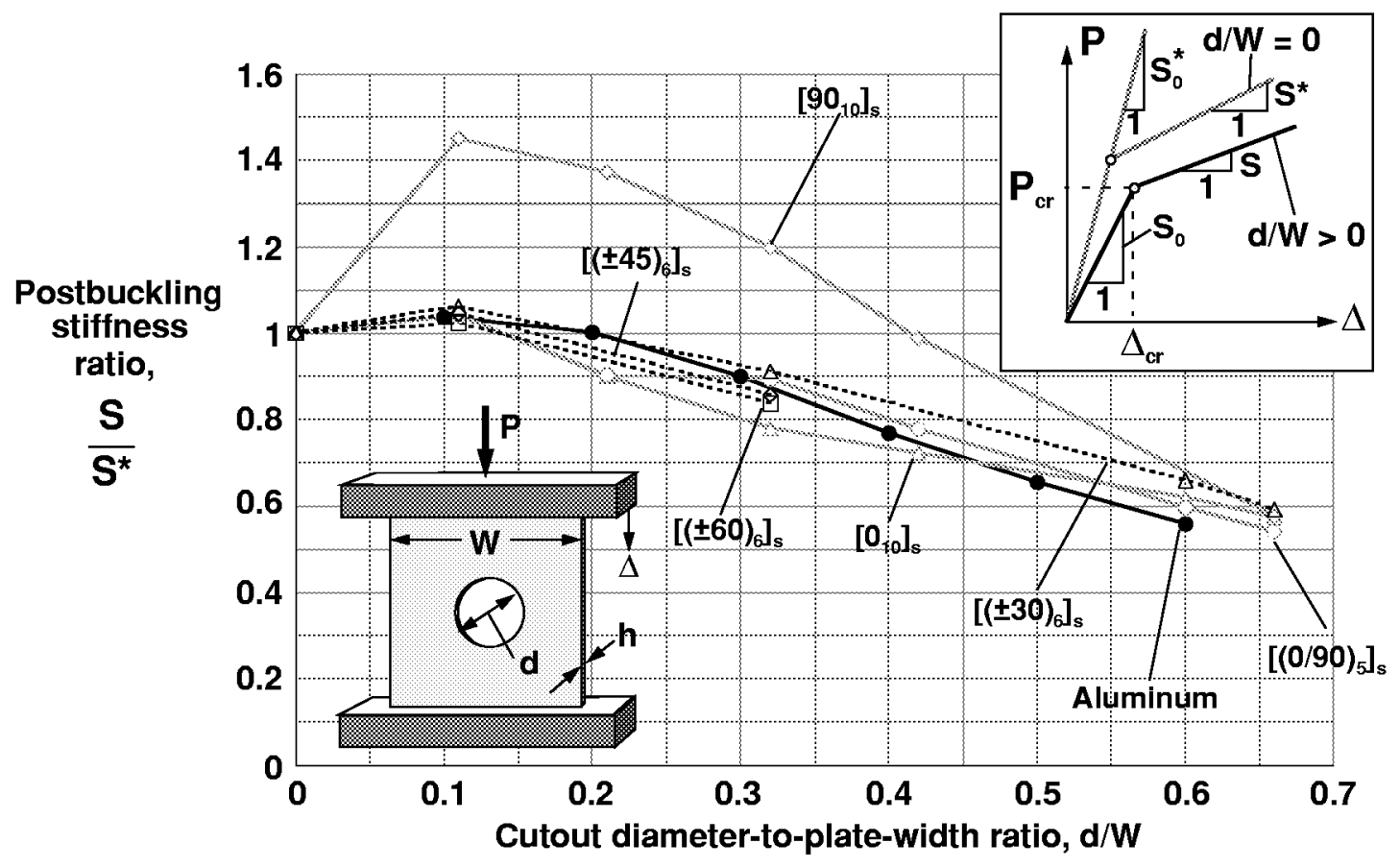

Fig. 11 Postbuckling stiffness ratios for perfectly flat, square aluminum and laminated-composite plates, with and without a central circular cutout, obtained from finite-element analyses.

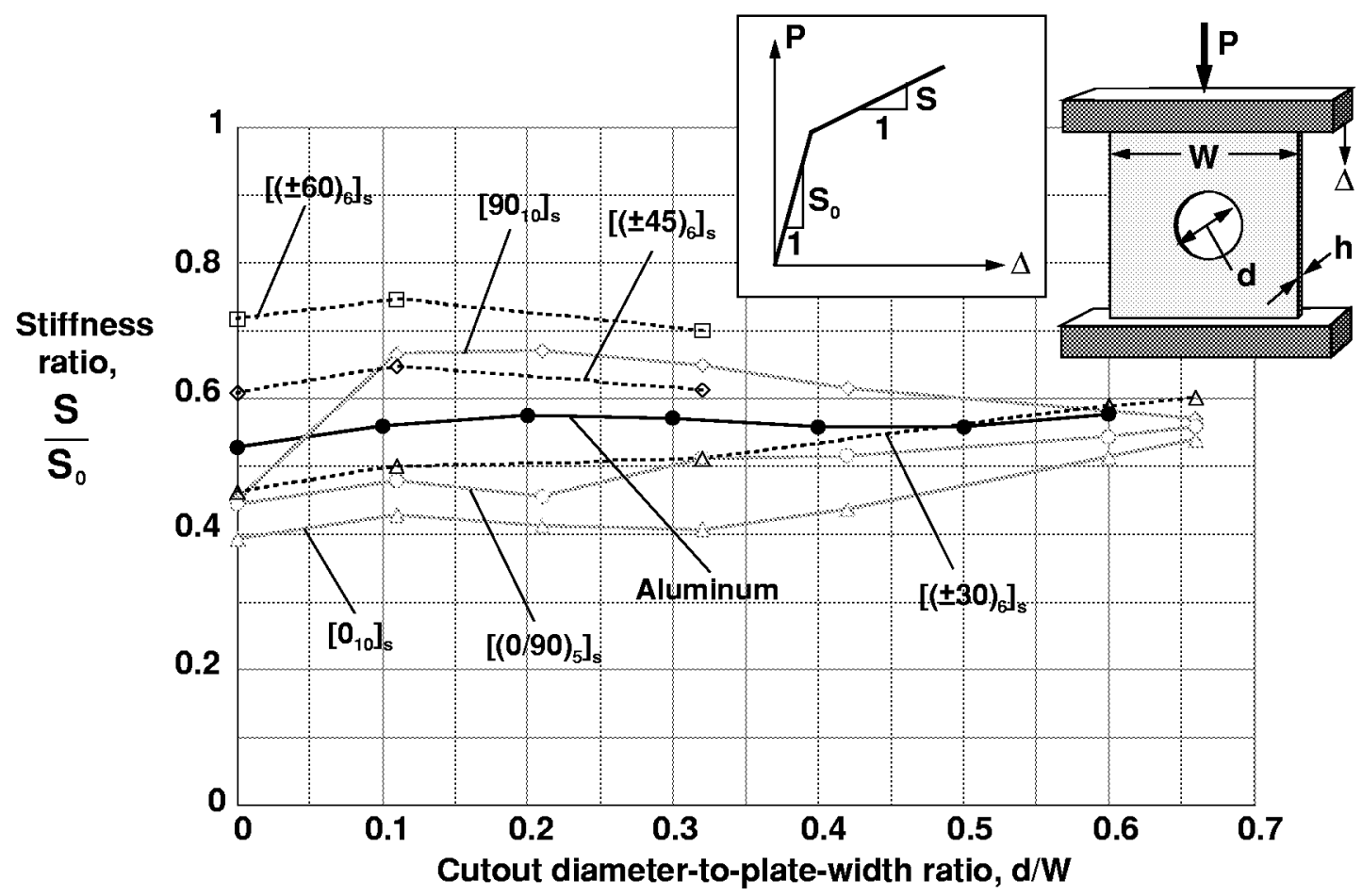

Fig. 12 Postbuckling-to-prebuckling stiffness ratios for perfectly flat, square aluminum and laminatedcomposite plates, with and without a central circular cutout, obtained from finite-element analyses. 


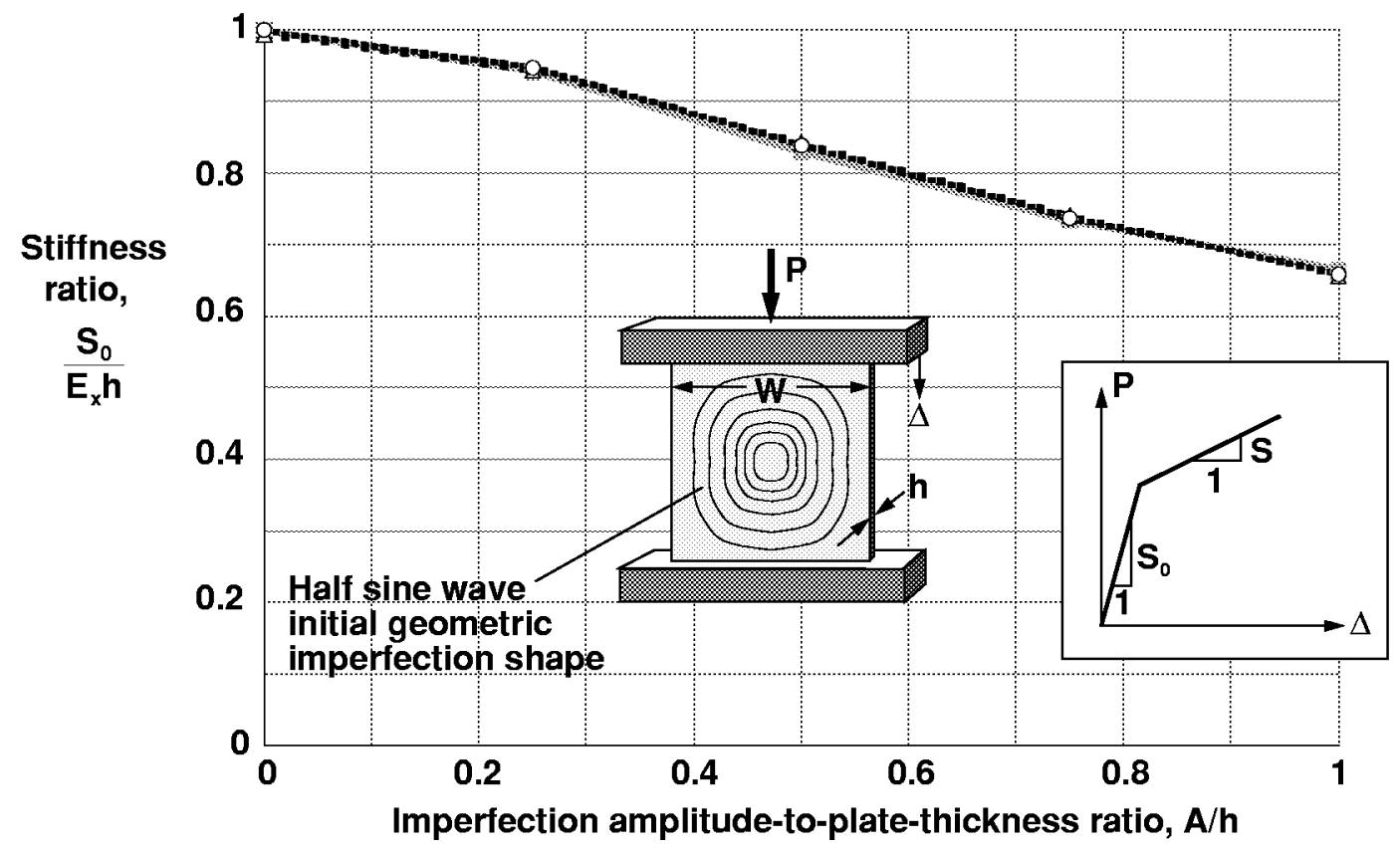

Fig. 13 Effect of imperfection amplitude on prebuckling stiffness ratio for square aluminum plates and $\left[0_{10}\right]_{s}$ and $\left[90_{10}\right]_{s}$ graphite-epoxy plates without a central circular cutout.

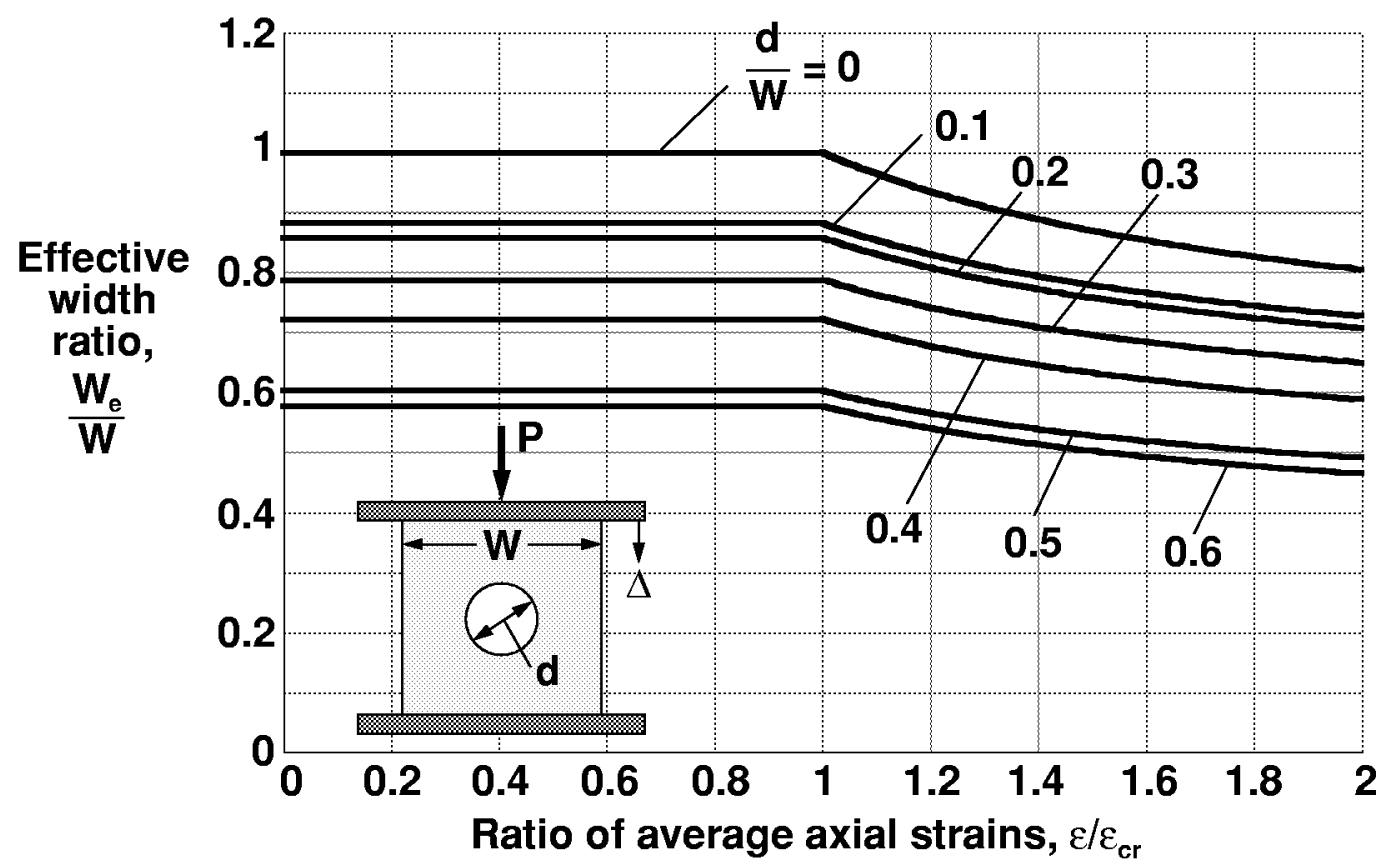

Fig. 14 Experimentally determined effective-width ratios for square aluminum plates with and without a central circular cutout. 


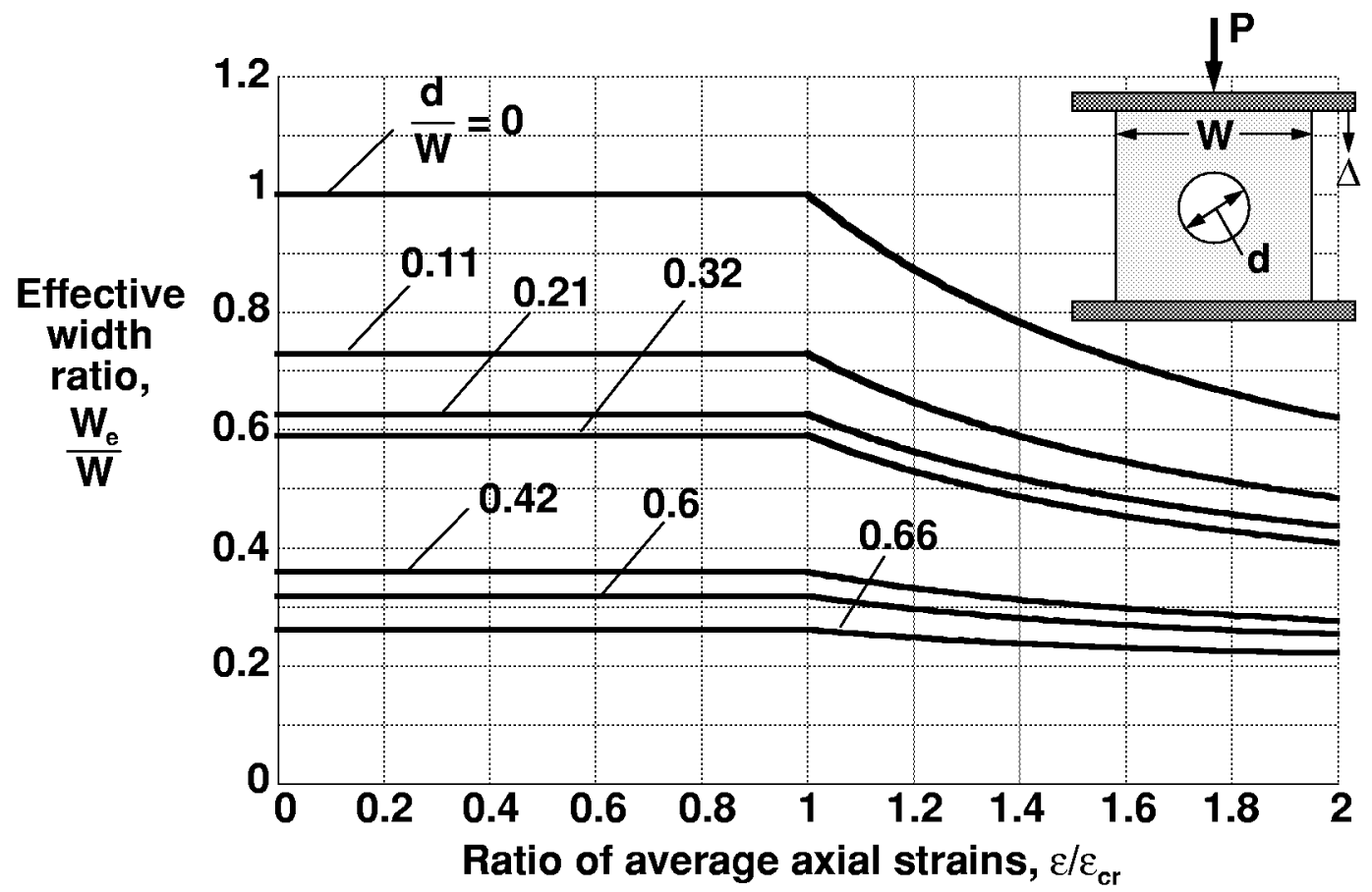

Fig. 15 Experimentally determined effective-width ratios for square $\left[0_{10}\right]_{s}$ graphite-epoxy plates with and without a central circular cutout.

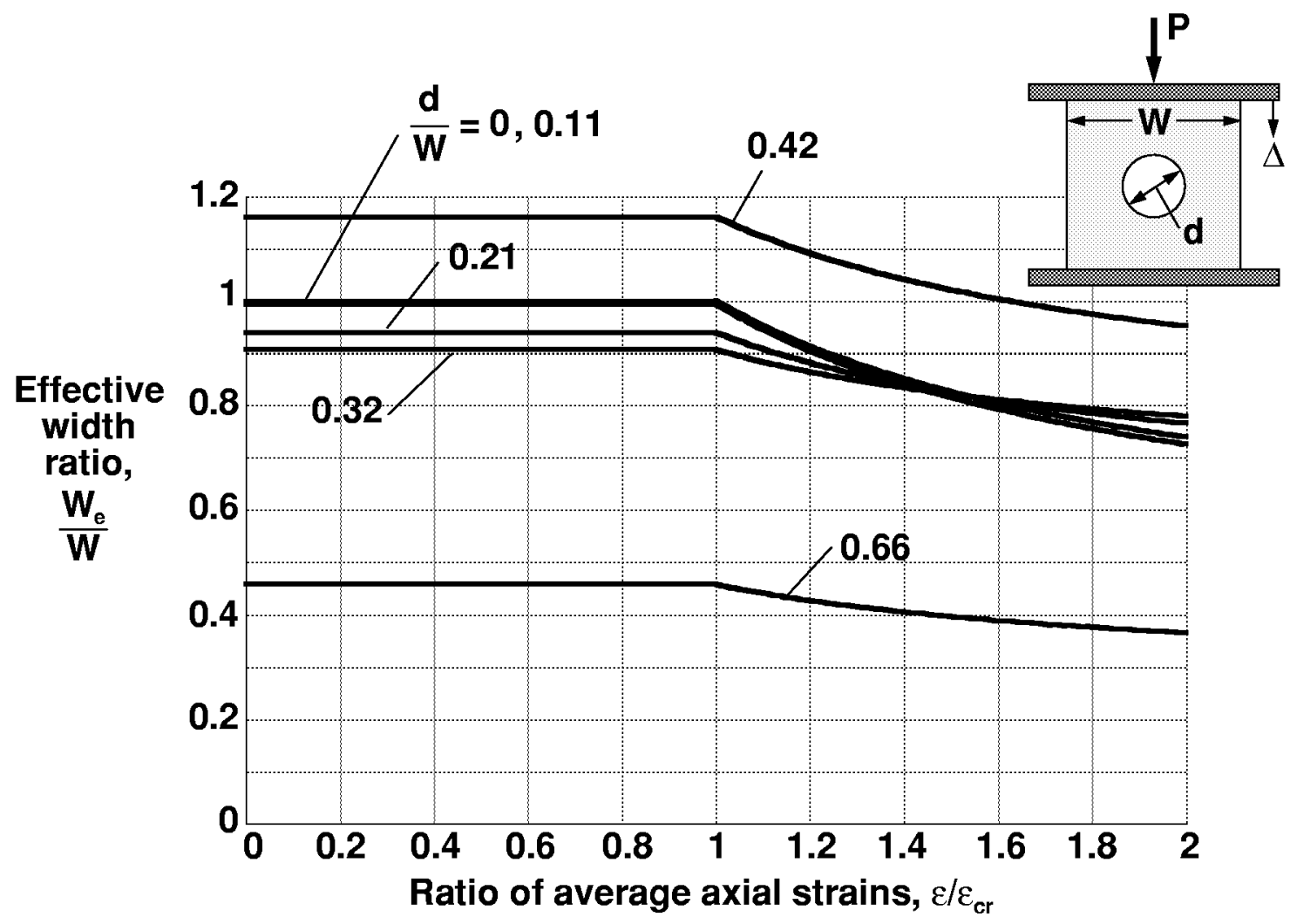

Fig. 16 Experimentally determined effective-width ratios for square $\left[90_{10}\right]_{s}$ graphite-epoxy plates with and without a central circular cutout. 


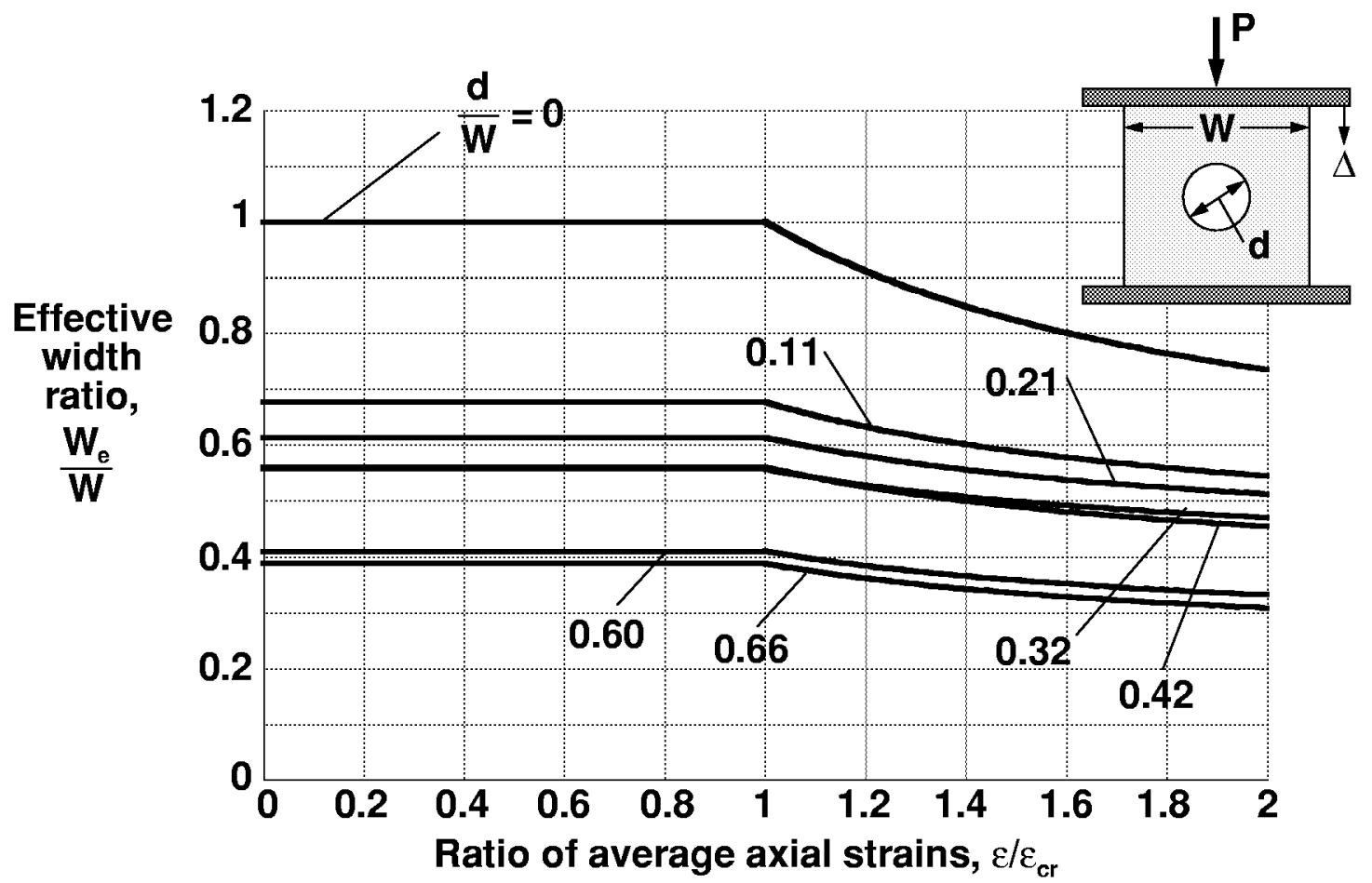

Fig. 17 Experimentally determined effective-width ratios for square $\left[(0 / 90)_{5}\right]_{s}$ graphite-epoxy plates with and without a central circular cutout.

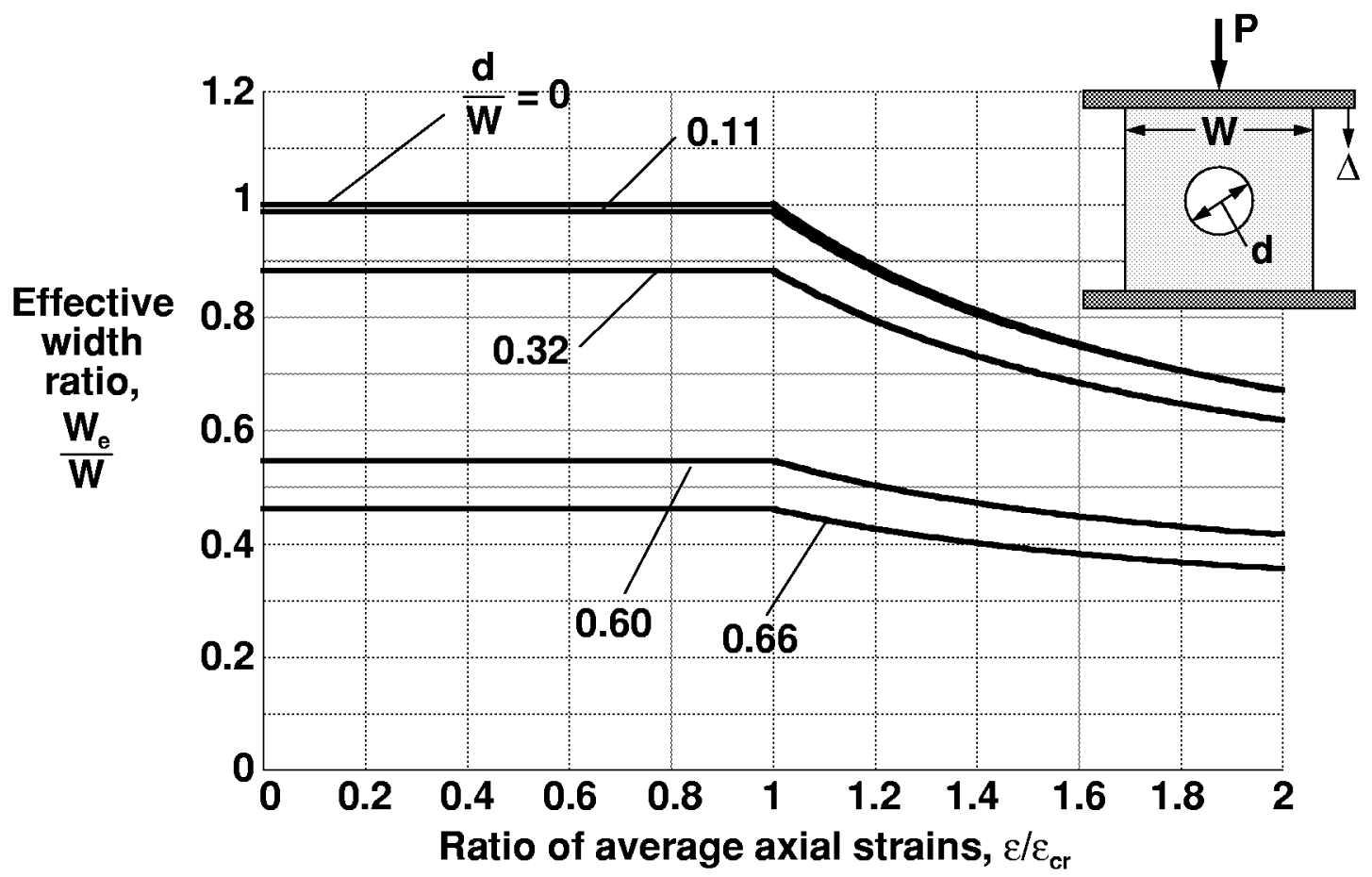

Fig. 18 Experimentally determined effective-width ratios for square $\left[( \pm 30)_{6}\right]_{\mathrm{s}}$ graphite-epoxy plates with and without a central circular cutout. 


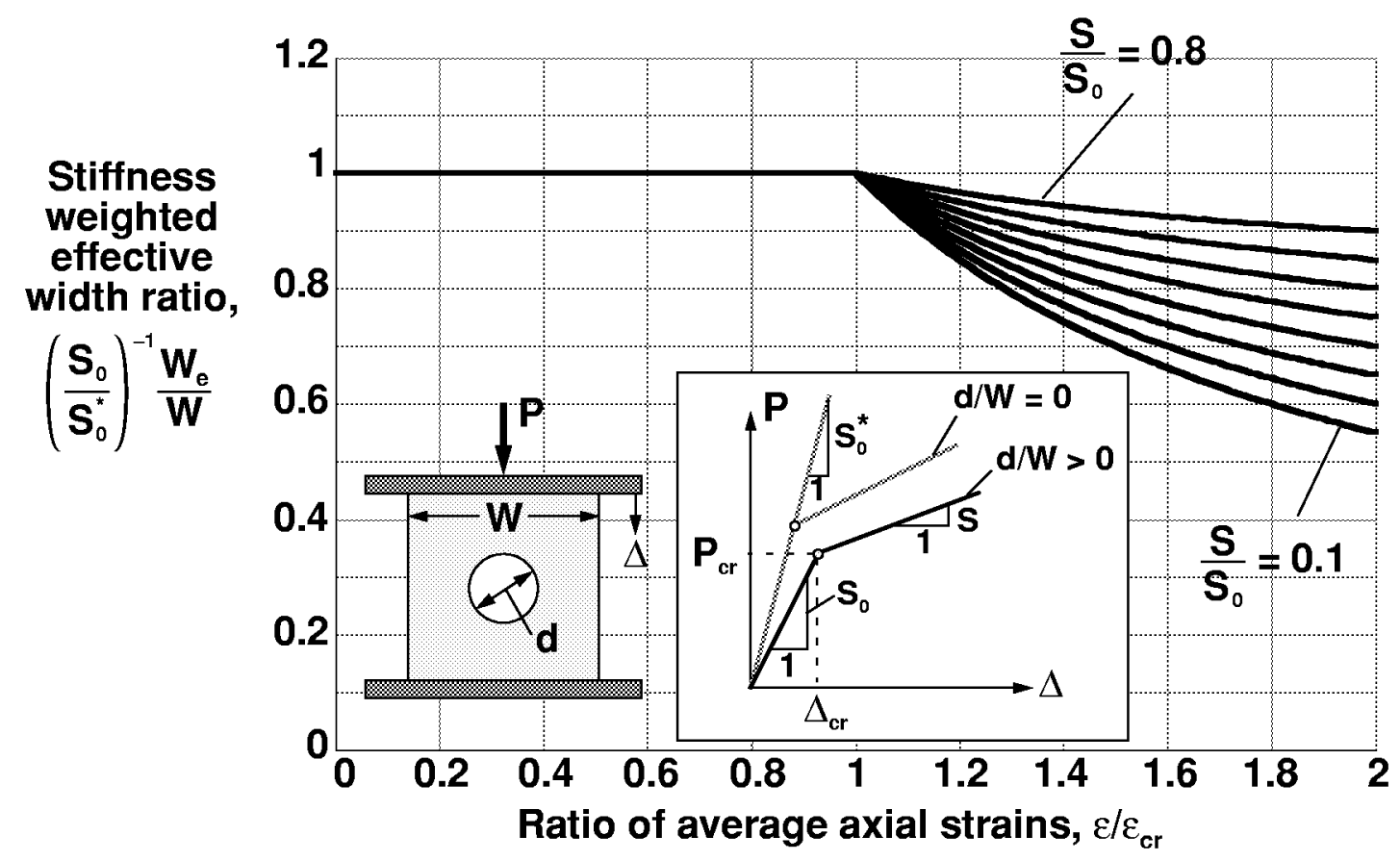

Fig.19 Stiffness weighted effective-width ratios for plates with and without a central circular cutout. 


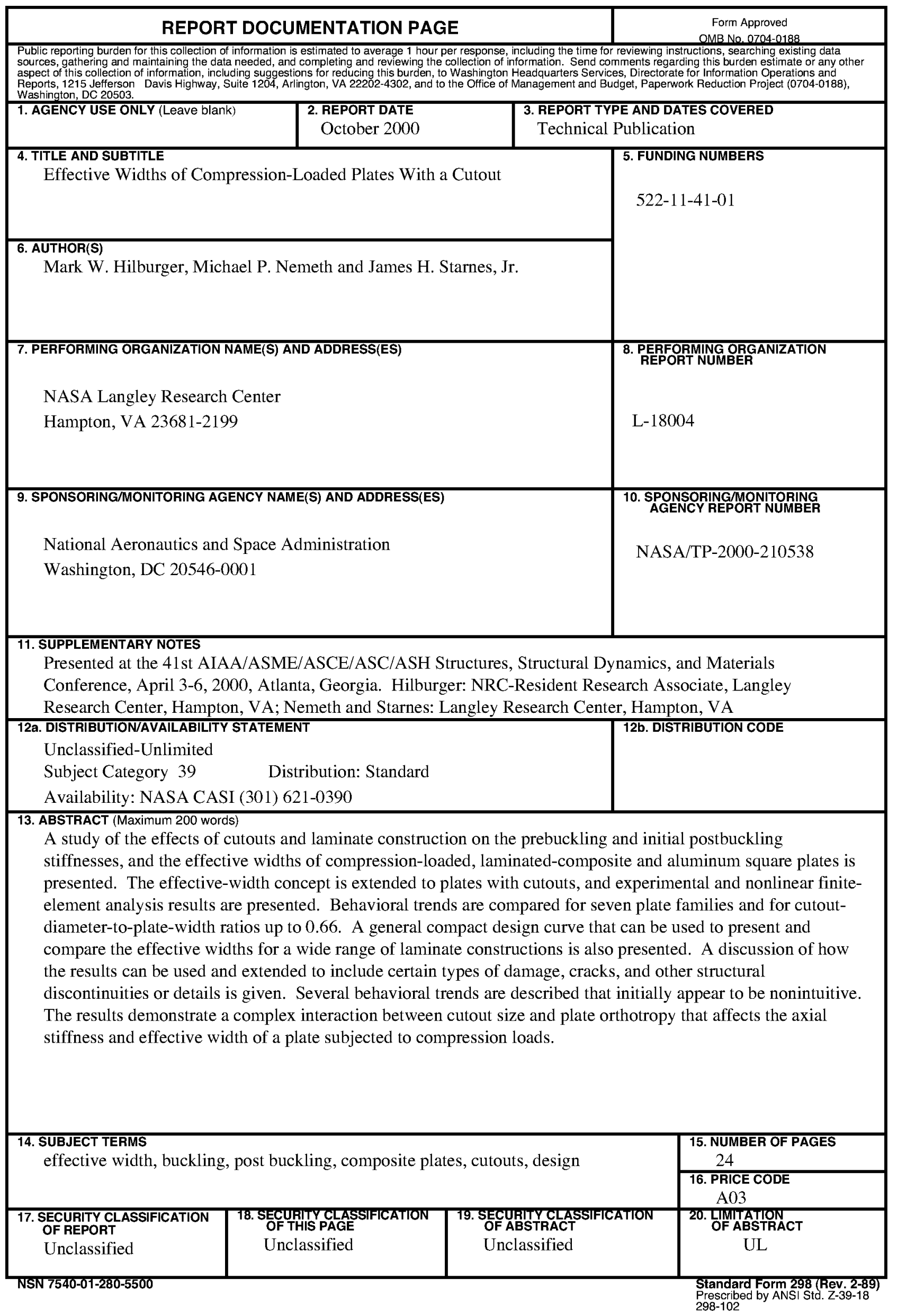

